Research Article

\title{
Numerical Investigation on Dynamic Performance of a Bridge-Tunnel Transition Section with a Deep Buried Pile-Plank Structure
}

\author{
Shuanglong Li $\mathbb{D}^{1},{ }^{1}$ Limin Wei $\mathbb{D}^{1,2}$ Xiaobin Chen, ${ }^{1,2}$ and Qun He $\mathrm{H}^{1,2}$ \\ ${ }^{1}$ School of Civil Engineering, Central South University, Changsha, Hunan 410075, China \\ ${ }^{2}$ National Engineering Laboratory for High Speed Railway Construction, Central South University, Changsha, \\ Hunan 410075, China
}

Correspondence should be addressed to Limin Wei; lmwei@csu.edu.cn

Received 15 June 2020; Revised 3 September 2020; Accepted 18 September 2020; Published 30 September 2020

Academic Editor: Giovanni Garcea

Copyright (C) 2020 Shuanglong Li et al. This is an open access article distributed under the Creative Commons Attribution License, which permits unrestricted use, distribution, and reproduction in any medium, provided the original work is properly cited.

To address the track irregularity at transition zones between subgrade and rigid structures (bridge, tunnel, etc.), some common transition approaches, such as trapezoid subgrade, were adopted in many engineering areas. However, in regard to a mountainous area, the common transition approaches may not be practicable anymore due to the limitation of the length between subgrade and rigid structures. In this paper, a new type of bridge-tunnel transition section with a deeply buried pile-plank structure (DBPPS) for short-distance transition is introduced. A three-dimensional finite element model that considers vehicle-track-subgrade coupling vibration is proposed to study the dynamic performances of a DBPPS transition section in the Shanghai-Kunming high-speed railway. With this model that has been validated with measured responses from field tests, the dynamic responses and the smoothness in track stiffness along the transition zone are analyzed. In addition, the influences of train speed, axle load, and train direction on dynamic responses are investigated, and the influences of two optimization strategies, including varying-length piles and constant-length piles, on the stiffness smoothness of the DBPPS transition section are discussed. Results show that the vibration level of the DBPPS transition section is lower than that of the abutment and the tunnel, and the additional load caused by vertical track stiffness difference aggravates the vibration at the connections between the DBPPS transition section and the abutment (or tunnel). Furthermore, the smoothness in stiffness along the transition zone can be significantly improved by the improvement strategy with varying-length piles.

\section{Introduction}

Because of two main factors [1-3] such as (i) vertical stiffness difference caused by different support conditions; (ii) settlement deformation difference between subgrade and rigid structures, the subgrade and track components in the transition zone showed higher degradation rates, resulting in more maintenance costs and worse passenger comfort [4]. Canada, China, and Europe [5-8] have published corresponding technical specifications to address this problem, so as to alleviate the degradation rates of the subgrade and track components. Meanwhile, many scholars have studied the dynamic performances of transition sections for different forms, such as subgrade-bridge transitions [2, 9-12], subgrade-tunnel transitions [13], subgrade-culvert transitions $[14,15]$, and cut-fill transitions on buried culverts [16].

Currently, the problems of track irregularity in subgrade-bridge (or tunnel) transition zones are more prominent [17]. To achieve a smooth transition of track stiffness between subgrade and bridge or tunnel, trapezoidal transition section is recommended in the code, China [8], and it is specified that the length of the transition section between subgrade and bridge shall not be less than $20 \mathrm{~m}$ (see Figure 1(a)), and the length of transition section between bridge and tunnel shall not be less than $40 \mathrm{~m}$ (see Figure 1(b)). However, when it comes to a mountainous area, the actual distance between bridge and tunnel may be even smaller than the length requirement specified in the 


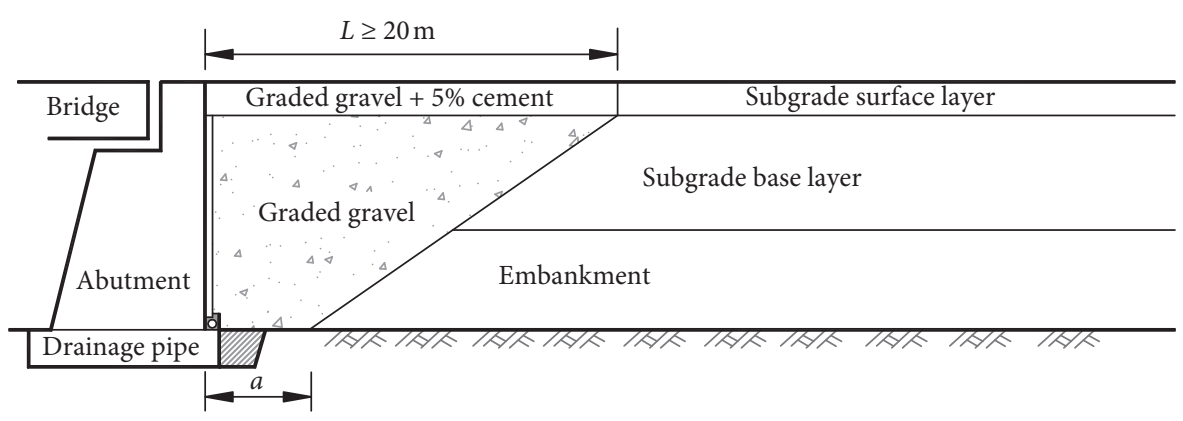

(a)

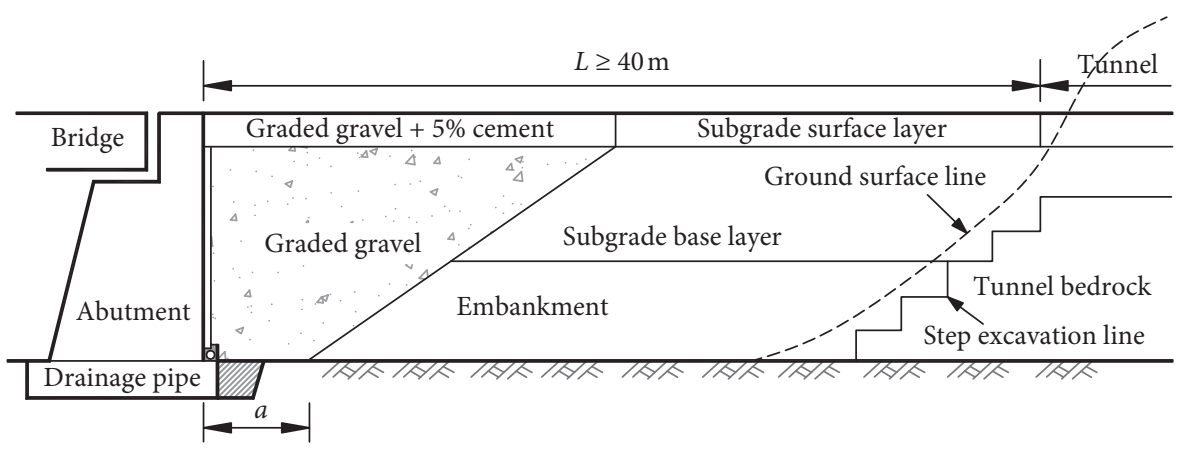

(b)

Figure 1: Schematic diagram of specified length for transition section in the code [8]. (a) The transition section between subgrade and bridge. (b) The transition section between bridge and tunnel.

code [8], and the trapezoidal transition section is not practicable anymore. As a typical transition section in Shanghai-Kunming high-speed railway, China, the length of the transition section between bridge and tunnel is only $26.0 \mathrm{~m}$. In this case, a deeply buried pile-plank structure (DBPPS) subgrade was applied to achieve a short-distance transition (see Figure 2) [18].

For the pile-plank structure, some studies have focused on its dynamic responses and load transfer behaviors in the general subgrade. Su et al. [19] carried out a field test on a nonburied pile-plank structure (NBPPS) subgrade. They indicated that the upper load can be transferred to a deeper bearing layer by the NBPPS. Zhan et al. [20] proposed a design method of NBPPS subgrade based on the ultimate limit state and serviceability limit state and studied the dynamic characteristics of the NBPPS subgrade. The results are in general agreement with those of Su et al. [19]. Ma [21] developed a three-dimensional finite element model that considers NBPPS-foundation coupled vibration to analyze the dynamic characteristics of the NBPPS subgrade, but the model could not reflect the effect of the train-track interaction. In addition, Huang et al. [22] carried out a centrifugal model test to investigate the settlement deformation of DBPPS subgrade under soft ground conditions, and found that the settlement deformation mainly occurs during the construction period with a settlement ratio that exceeds $80 \%$. Huang et al. [23] carried out excitation tests on a DBPPS subgrade and found that the DBPPS subgrade exhibits good dynamic performance.

Nevertheless, it should be noted that there is no discussion in the literature on the dynamic performances of the
DBPPS subgrade used to transition sections (such as the bridge-tunnel transition section). As a new type of transition section, its dynamic characteristics and transition performances are worthy of further study. In this study, a threedimensional (3D) finite element (FE) model considering vehicle-track-subgrade coupling vibration is proposed to investigate the dynamic performances of a bridge-tunnel transition zone with a DBPPS in the Shanghai-Kunming high-speed railway, and the model is validated by measured responses from field tests. With this model, some topics related to the vertical track stiffness distribution, dynamic performance, and structural optimization of the DBPPS transition section are discussed. The conclusions of this study may be helpful for the design and optimization of the DBPPS transition section.

\section{Description of the Case Study}

The present case study is the transition zone in the Shanghai-Kunming high-speed railway in China, as shown in Figure 2. The line comprises a double-block ballastless track (China Railway Track System II, see Figure 3) using continuously welded U71MnG type rails with a unit weight of $60 \mathrm{~kg} / \mathrm{m}$, concrete sleepers with a spacing of $0.65 \mathrm{~m}$. The design speed of the line is $350 \mathrm{~km} / \mathrm{h}$ and the operation speed is $300 \mathrm{~km} / \mathrm{h}$.

The length between the abutment and the filled concrete layer is only $26.0 \mathrm{~m}$. According to the code [8], the limited distance leads to the common transition section mentioned above that is not practicable. To reduce the amount of soil excavation and engineering cost, a DBPPS subgrade is 


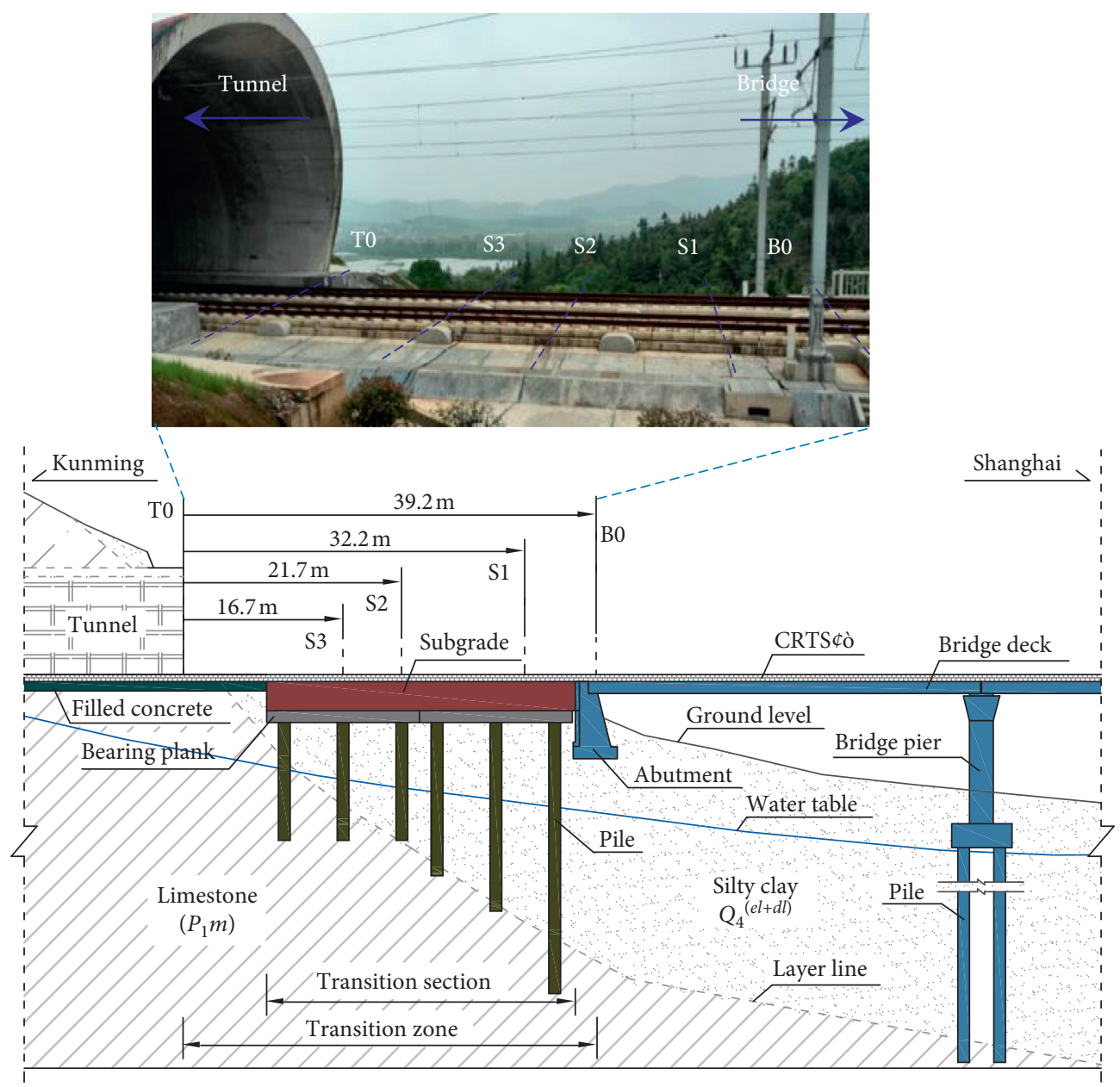

(a)
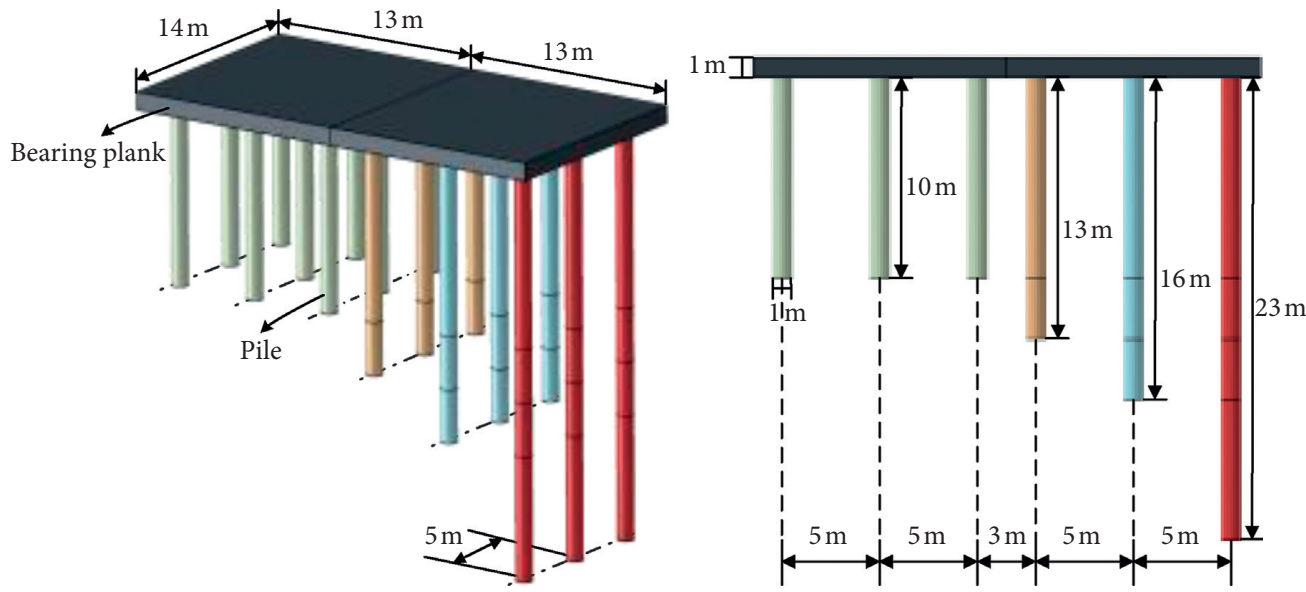

(b)

FIGURE 2: Schematic profile of the transition zone. (a) Longitudinal profile of the transition zone. (b) Detailed components of the pile-plank structure.

adopted to achieve a short-distance transition. The DBPPS consists of piles and bearing planks, which are used to support the upper track structure. It is set below the subgrade base layer and divided into two parts by joints (see Figure 2(b)). The bearing planks are reinforced concrete structure, which is rigidly coupled with the cast-in-situ bored piles. To facilitate description, in this case study, the section including the tunnel entrance, the DBPPS subgrade, and the abutment is named transition zone, and the DBPPS subgrade is named transition section (Figure 2(a)).

Two layers with different fillers are laid on the pile-plank structure, as shown in Figure 3. The subgrade base layer with 


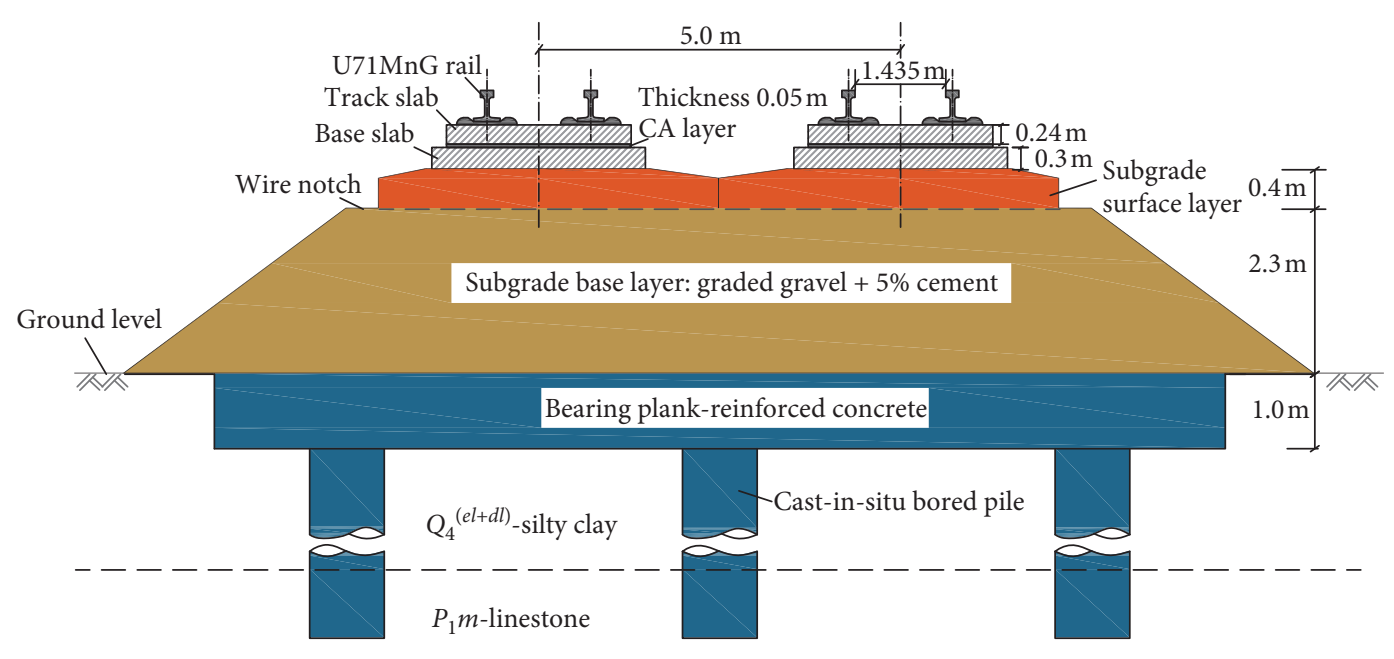

FIGURE 3: Transverse profile of the transition section.

a thickness of $2.3 \mathrm{~m}$ was filled with graded gravel $+5 \%$ cement, and the subgrade surface layer with a thickness of $0.4 \mathrm{~m}$ was filled with graded gravel. $\mathrm{Hu}$ et al. [15] previously carried out a series of laboratory tests and field tests to evaluate the particle size, strength indices, and dynamic properties of the fillers. The test results showed that the dynamic elastic modulus, Poisson's ratio, cohesion, and internal friction angle of graded gravel $+5 \%$ cement were $1.78 \mathrm{GPa}, 0.30,1.326 \mathrm{MPa}$, and $45.8^{\circ}$, respectively. Correspondingly, the values of graded gravel were $1.58 \mathrm{GPa}, 0.24$, $0.16 \mathrm{MPa}$, and $39.5^{\circ}$, respectively. These parameters would be applied to the FE model in this study.

The natural foundation of the transition zone consists mostly of a silty clay layer with a gradually changing depth and limestone layer (Figure 2(a)). To adapt the stiffness variations between the transition section and the abutment, an improvement strategy with varying-length piles in the pile-plank structure is adopted. Actually, the stiffness difference between the transition section and the abutment (or the tunnel) is inevitable, but the keys aspect of this study are that it contributes to understanding the adverse effects caused by the stiffness difference on the track and to evaluating whether the transition section can meet the requirements of line smoothness.

\section{Numerical Model considering Vehicle-Track- Subgrade Interaction}

3.1. Model Establishment. To adequately reproduce the behavior and geometry of the problem in the DBPPS transition zone, a 3D FE model was developed with ABAQUS ${ }^{\circledR}$ software [24] using an element mesh as close as was deemed necessary. The connections between the DBPPS subgrade and the abutment or tunnel are important positions for observation of dynamic responses. Therefore, a tunnel section and a bridge section in the FE model were established to connect the DBPPS subgrade (Figure 4(a)). All model components were discretized using a three-dimensional reduced integrated solid element (C3D8R).
To obtain accurate simulation results, the mechanical contacts between the pile-plank structure and the surrounding soil should be defined properly. In this study, contact elements were attached at the interfaces between the pile-plank and the surrounding soil (see Figure 4(b)). A "hard contact" that considers the pressure-overclosure relationship was adopted to simulate the normal behavior of contact elements. The contact pressure would occur only when two surfaces were in contact. Moreover, a "penalty function" with a friction coefficient of 0.3 was adopted to simulate the tangential behavior of contact elements.

Linear spring-dashpot elements were attached between the rail and the track slab to simulate the fasteners with a spacing of $0.65 \mathrm{~m}$ (Figure 4(a)). The vertical stiffness of the fastener was $60 \mathrm{MN} / \mathrm{mm}$ and the damping was $60 \mathrm{kN} \mathrm{s} / \mathrm{m}$ [25]. To reflect the dynamic interaction of wheel-rail, a nonlinear elastic contact theory proposed by Hertz [26] was adopted to describe normal behavior. The normal force of wheel-rail interaction could be obtained by the following formula [26]:

$$
P(t)=\left[\frac{1}{G} \Delta z(t)\right]^{3 / 2},
$$

where $P(t)$ is the normal force of wheel-rail interaction; $G$ is the wheel-rail contact constant, the value is related to the outer profile of the wheel tread, and $\Delta z(t)$ is the normal elastic compression deformation between wheel and rail. For the wheel with a worn type tread, the constant $G$ could be addressed by the following [27]:

$$
G=3.86 R^{-0.115} \times 10^{-8}
$$

where $R(\mathrm{~m})$ is the radius of the wheel, the value is $0.46 \mathrm{~m}$ in this study. Subsequently, the relationship curve between $P(t)$ and $\Delta z(t)$ could be obtained, as shown in (Figure 4(c)). In this study, contact elements were attached at the interfaces between the wheel tread and the rail, which took the tread surface as the master surface and the rail surface as the slave surface (Figure 4(d)). Meanwhile, a "soft contact" model that considered the relationship between $P(t)$ and $\Delta z(t)$ using a 


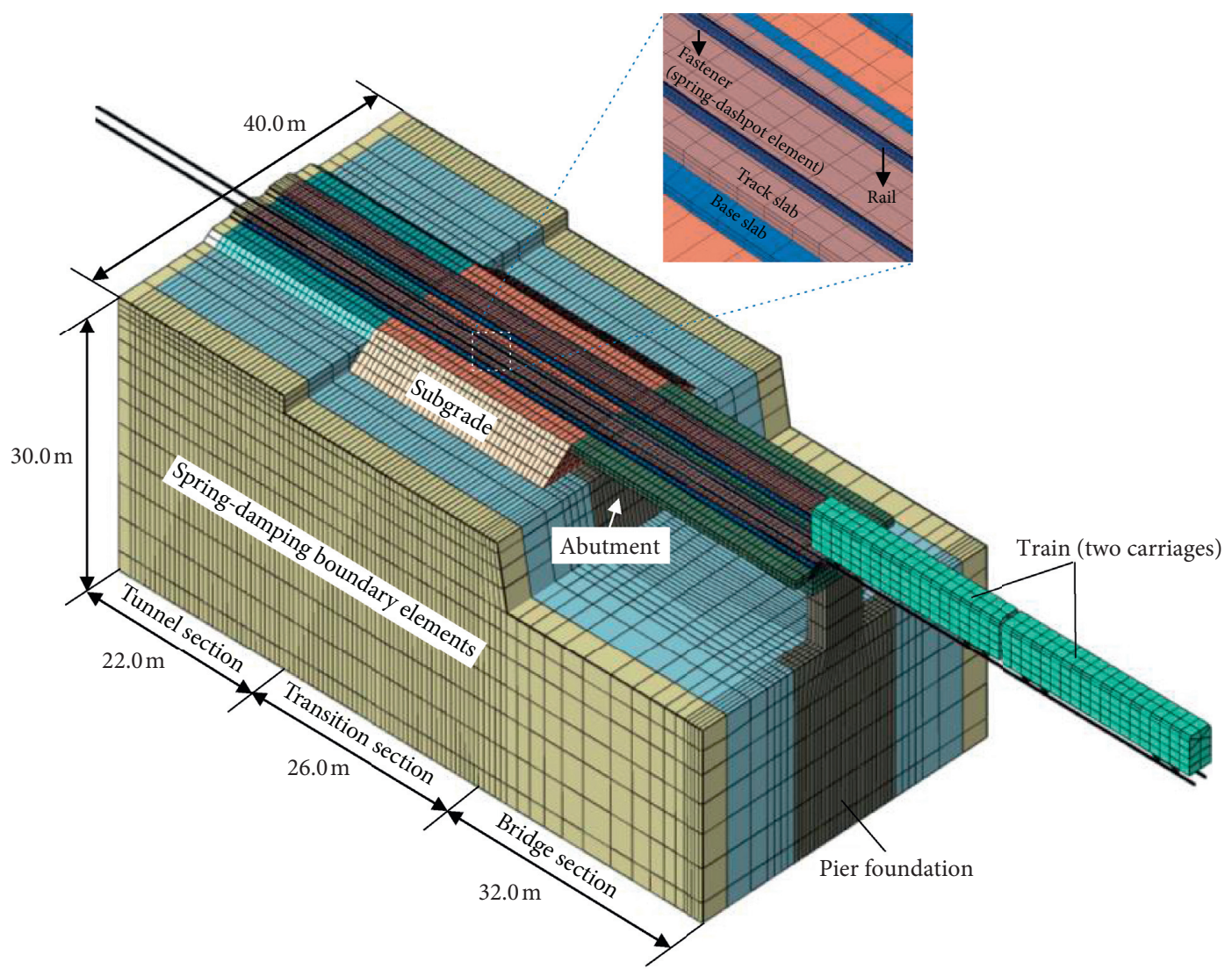

(a)

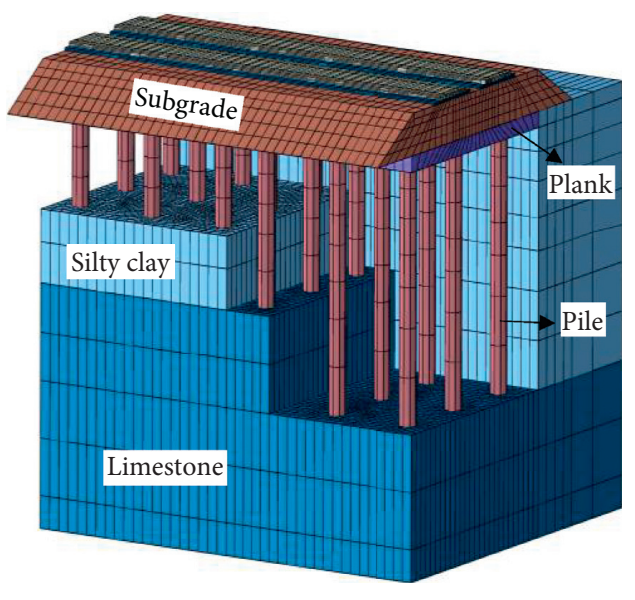

(b)

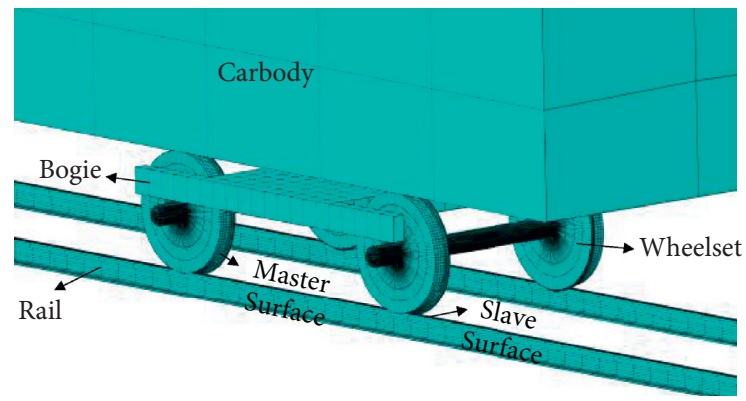

(d)

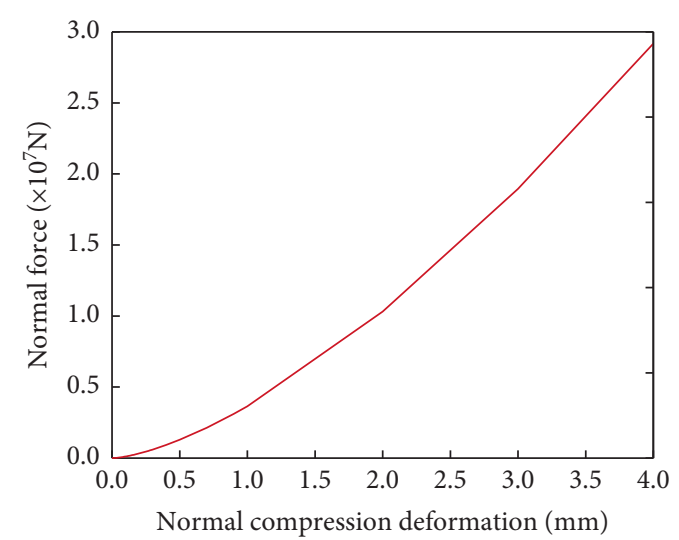

(c)

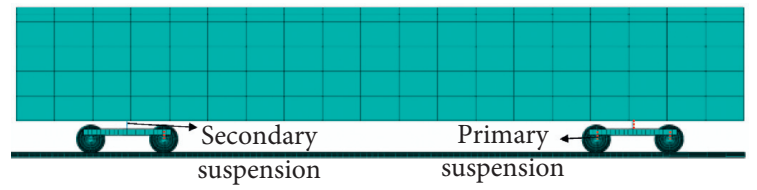

(e)

FiguRE 4: Finite element model. (a) Full model. (b) Grid of pile-plank and surrounding soil. (c) Relationship between normal force and compression deformation. (d) Contact elements between the wheel tread and the rail. (e) Vehicle model. 
"Tabular" type in ABAQUS was proposed to simulate the normal behavior of the wheel-rail interaction. With this setting, the change rate of the wheel-rail contact force would be slowed down, which was beneficial to the convergence of the calculation. For the tangential behavior of the wheel-rail interaction, a "penalty function" model with a friction coefficient of 0.2 was adopted. Considering that the rail was newly laid, it was regarded as an idealized horizontal track in the model.

To reflect the coupling vibration inside the vehicle, the doubled suspension system was considered. Based on the theoretical model proposed by Zhai $[28,29]$ for investigating vertical interactions between railway vehicle and track, the vehicle in this model was simplified to be composed of wheelsets, bogies, and carbodies. Connector elements with elastic-damping properties were adopted to simulate the suspension systems between the wheelsets and bogies, and between the bogies and carbody (Figure 4(e)). Considering the influence of adjacent wheelsets on wheel-rail interaction, two carriages of the vehicle were selected in the model. The simulation of train speed was realized by applying the velocity (including translation velocity and rotation velocity) to the carbodies, bogies, and wheelsets along the rails.

In general, to reduce the reflection of stress waves at the model boundary, the model size should be as large as possible, but more time and computer resources would be costly. To address this problem, many scholars introduced an artificial boundary for simulation analysis. Currently, there are two mainstream modeling methods to minimize the reflected dynamic wave at the boundary: (i) using infinite elements at the boundary and setting viscous property between finite and infinite elements [30,31], and (ii) introducing an artificial spring-damping boundary to absorb the dynamic wave $[12,15,32]$. In this study, the viscoelastic artificial boundaries were adopted to reproduce the dynamic response using springdamping elements. These spring-damping elements were applied in the boundary components in three directions at each node. The normal damping coefficient and stiffness coefficient were determined according to the test results carried out by $\mathrm{Hu}$ et al. [15]. Besides, the bottom boundary of the model was fixed by a three-degree-of-freedom displacement constraint, and the lateral and longitudinal boundaries were constrained by normal displacements.

In this model, the fillers in subgrade layers were modeled as Mohr-Coulomb material to consider the possibility of plastic yield in the subgrade under heavy axle load (such as more than $30 \mathrm{t}$ ), and the other components were modeled as linear-elastic material. The parameters of different materials are shown in Table 1. The Rayleigh damping was adopted to describe the damping properties of the components in the transition zone; the mass matrix coefficient $\alpha$ and stiffness matrix coefficient $\beta$ are referenced from [33]. To obtain accurate calculation results, the dynamic implicit algorithm was adopted with a maximum time step of $2.5 \mathrm{~ms}$.

\subsection{Model Validation with Field Tests}

3.2.1. Field Tests. To validate the FE model, field tests were carried out. The 891-II type vibration sensors (Figure 5(a)) were applied to measure the horizontal and vertical dynamic responses including acceleration and velocity. The acceleration measurement range is $\pm 40 \mathrm{~m} / \mathrm{s}^{2}$ with a sensitivity of $0.1 \mathrm{~V} \mathrm{~s}^{2} / \mathrm{m}$ ( $\mathrm{V}$ is a voltage unit), and the velocity measurement range is $\pm 0.5 \mathrm{~m} / \mathrm{s}$ with a sensitivity of $30.0 \mathrm{~V} \mathrm{~s} / \mathrm{m}$. The vibration signals were collected by an INV3060D type acquisition analyzer (Figure 5(b)). With the vibration sensors, data acquisition analyzer, and network module, data acquisition and wireless transmission test system for automatic train triggering was established. Measuring sections of B0, S1, S2, S3, and T0 were established for the attempt to reflect the variations of dynamic responses along the transition zone. Section B0 was set at the abutment, section T0 was set at the tunnel entrance, and sections of S1, S2, and S3 were set at the DBPPS subgrade (see Figures 2(a) and 5(c)). The vibration sensors were placed on the center of the subgrade, on both sides of the base slab and on the slope of the subgrade to investigate the transverse distribution of the dynamic response (Figure 5(d)).

The CRH380AM type trains with an axle weight of $15.0 t$ and a speed range of $236-335 \mathrm{~km} / \mathrm{h}$ were tested. The schematic profile of CRH380AM type train is depicted in Figure 6. As an example, the test results of this type of train were selected to verify the reliability of the FE model, and the vehicle parameters are shown in Table 2.

It is worth explaining that the field tests were carried out during the period of the joint commissioning test, which means that the railway line was not officially operated in that period. Therefore, there is no significant uneven permanent settlement deformation that occurred in the transition zone during the field tests. In the FE model, the influence of stiffness variations along the transition zone on dynamic response is considered, while the influence of permanent settlement deformation is ignored.

\subsubsection{Comparison between Numerical Results and Field} Measurement. The test results of the CRH380AM train with a running speed of $300 \mathrm{~km} / \mathrm{h}$ from a bridge to a tunnel are compared with the numerical results for validation. Figure 7 shows the comparison of vertical acceleration and velocity time-history curves at measuring points $\mathrm{B} 0-3, \mathrm{~S} 2-3$, and $\mathrm{T} 0$ 3 between the numerical results and the field measurement. These signal curves have been filtered with a cutoff frequency of $120 \mathrm{~Hz}$. It can be seen that the amplitude and the curve trend of the numerical results are in good agreement with the measured results on the whole.

Figure 8 shows the comparison of vertical acceleration and velocity peaks between the numerical results and the field measurement. Considering the randomness of track vibration caused by the wheelsets, the measured peaks here are the average values of vibration peaks caused by two adjacent bogies (i.e., four wheelsets). It also indicates that the good agreement that is obtained between the numerical and the experimental vertical acceleration and velocity peaks, and the differences of vertical acceleration and velocity peaks between the numerical results and the field measurement are within $30 \%$ in most measuring points. However, a considerable difference is still observed at measuring points of section T0 on the base slab, such as T0-3 (Figures 7(a) and 
TABLE 1: Material properties of the components in the transition zone $[15,22,33]$.

\begin{tabular}{|c|c|c|c|c|c|}
\hline \multirow{2}{*}{ Components or material } & \multirow{2}{*}{ Young's modulus $E(\mathrm{MPa})$} & \multirow{2}{*}{ Poisson's ratio $\mu$} & \multirow{2}{*}{ Density $\rho\left(\mathrm{kg} / \mathrm{m}^{3}\right)$} & \multicolumn{2}{|c|}{ Rayleigh damping } \\
\hline & & & & $\alpha\left(\mathrm{s}^{-1}\right)$ & $\beta(\mathrm{s})$ \\
\hline Rail & 205,900 & 0.30 & 7,830 & 0.022 & 0.002 \\
\hline Track slab & 32,500 & 0.16 & 2,500 & 0.098 & 0.009 \\
\hline Base slab & 25,500 & 0.16 & 2,500 & 0.098 & 0.009 \\
\hline Graded gravel $+5 \%$ cement & 1,780 & 0.30 & 2,100 & 0.229 & 0.021 \\
\hline Graded gravel & 1,580 & 0.24 & 2,000 & 0.252 & 0.022 \\
\hline Bearing plank & 56,000 & 0.20 & 2,500 & 0.085 & 0.009 \\
\hline Cast-in-situ bores pile & 38,000 & 0.20 & 2,500 & 0.098 & 0.008 \\
\hline Silty clay & 15 & 0.30 & 1,930 & 0.262 & 0.024 \\
\hline Sand layer & 75 & 0.30 & 1,950 & 0.270 & 0.023 \\
\hline Limestone & 600 & 0.29 & 2,090 & 0.235 & 0.02 \\
\hline Abutment & 30,000 & 0.20 & 2,300 & 0.098 & 0.009 \\
\hline Bridge deck & 22,000 & 0.18 & 2,550 & 0.098 & 0.009 \\
\hline Tunnel filled concrete & 20,000 & 0.20 & 2,400 & 0.098 & 0.009 \\
\hline Tunnel bedrock & 12,000 & 0.20 & 2,300 & 0.15 & 0.015 \\
\hline
\end{tabular}
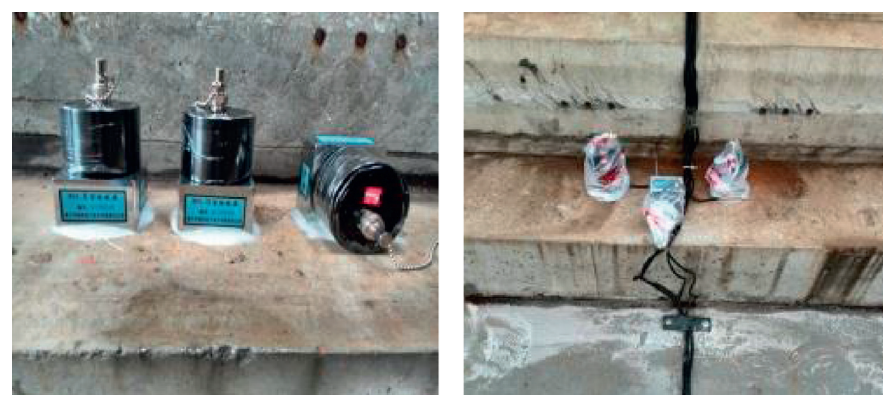

(a)

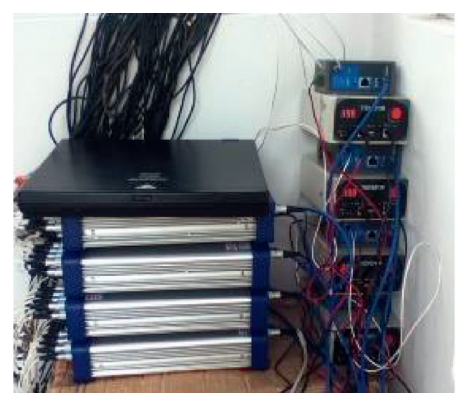

(b)

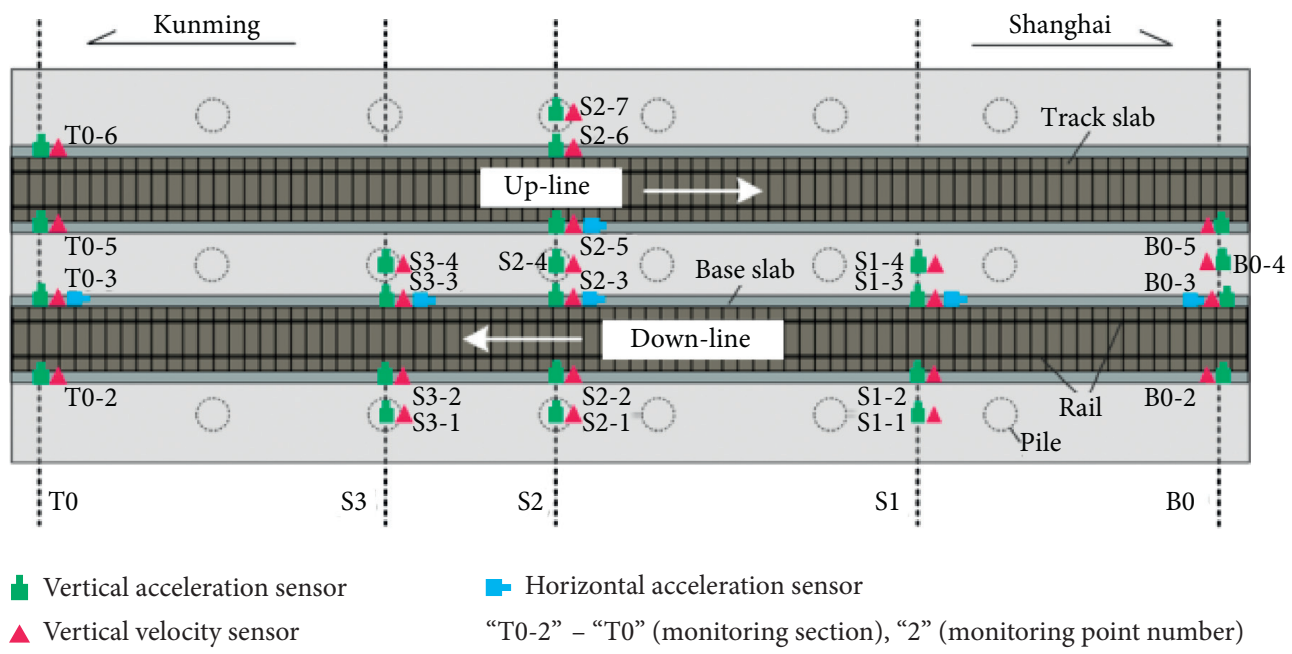

(c)

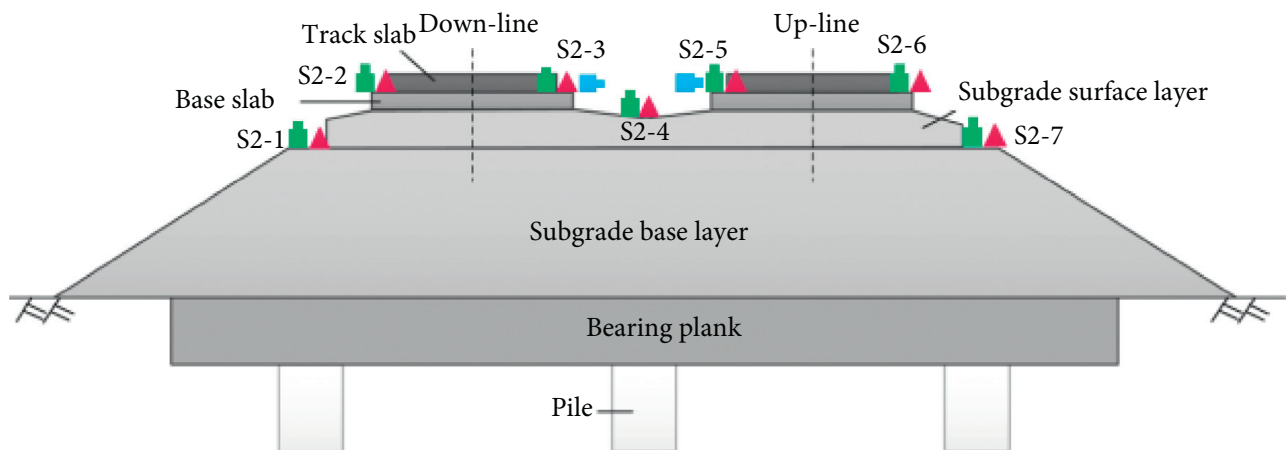

(d)

FIGURE 5: Measuring equipment and layout. (a) 891-II type vibration sensor. (b) INV3060D type acquisition analyzer and network module. (c) Layout of measuring points in the transition zone. (d) Layout of measuring points in the section S2. 


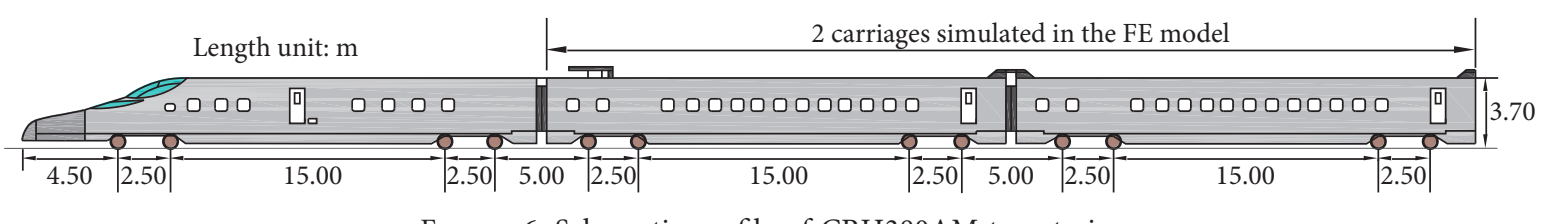

FIGURE 6: Schematic profile of CRH380AM type train.

Table 2: Parameters of the vehicle [25, 34].

\begin{tabular}{lc}
\hline Parameters & Value \\
\hline Mass of the carbody & $44320 \mathrm{~kg}$ \\
Mass of the bogie & $3136 \mathrm{~kg}$ \\
Mass of the wheelset & $2352 \mathrm{~kg}$ \\
Pitch inertia of the carbody & $5.20 \mathrm{e}^{5} \mathrm{kgm}$ \\
Pitch inertia of the bogie & $6400 \mathrm{kgm}$ \\
Stiffness of primary suspension & $1040 \mathrm{kN} / \mathrm{m}$ \\
Stiffness of secondary suspension & $400 \mathrm{kN} / \mathrm{m}$ \\
Damping of primary suspension & $40 \mathrm{kN} \cdot \mathrm{s} / \mathrm{m}$ \\
Damping of secondary suspension & $60 \mathrm{kN} \cdot \mathrm{s} / \mathrm{m}$ \\
\hline
\end{tabular}

8(a)). The differences of vertical acceleration peak and velocity peak at T0-3 between the numerical results and the field measurement are approximately $54.3 \%$ and $40.8 \%$, respectively. The main reason may be that an aerodynamic effect [35] is generated at the tunnel entrance when the train passes by, which aggravates the vibration of track components at section T0. But the effect is not well simulated in the numerical model, which induces a significant difference between the numerical results and the field measurement, especially in section T0.

\section{Results and Discussion}

4.1. Dynamic Response along the Transition Zone. Figure 9 shows the distribution of vertical acceleration on the base slab and the vertical track stiffness obtained from the formula proposed by [36] along the transition zone when the CRH380AM train moves from the bridge to the tunnel. It can be seen that the vertical acceleration of the DBPPS transition section is less than that of the abutment and the tunnel section. Compared with the tunnel section and the abutment, the fillers in the DBPPS subgrade have the properties of low stiffness and large damping, resulting in lower vibration levels in the DBPPS subgrade. Moreover, a considerable amplification effect for the vertical acceleration can be observed at the connections ( $x=10.2 \mathrm{~m}$ and $x=36.2 \mathrm{~m}$ ) between the transition section and the tunnel (or abutment). The authors consider that the amplification effect is caused by the abrupt change of wheel-rail interaction caused by the stiffness difference at the connections. This phenomenon was also found by Sanudo [37] and Shahraki [38].

It should be noted that the vertical acceleration of section S1 is higher than that of the sections S2 and S3. This can be explained that when the train passes through the connection between the abutment and the transition section with an abrupt change stiffness, an additional load on the track components is generated by the train load, which aggravates the vibration at the connection and its adjacent area, resulting in the vertical acceleration of section S1 being higher than that of sections S2 and S3.

Although the dynamic response at connections is intensified due to the amplification effect, the maximum vertical vibration acceleration of the transition zone is only $0.23 \mathrm{~m} / \mathrm{s}^{2}$, which is less than $5.0 \mathrm{~m} / \mathrm{s}^{2}$ specified in the code [8], indicating that the DBPPS transition section exhibits good dynamic performance.

The coupling vibration inside the vehicle is considered in the FE model, and the line smoothness of the transition zone can be evaluated by the dynamic response of the vehicle. Figure 10 shows the vertical acceleration distribution of the vehicle which is comprised of an axle, bogie, and carbody along the transition zone. Due to the dynamic contact interaction between the wheel and the rail, the acceleration amplitude of the axle changes more dramatically, and the vibration frequency is higher than that of bogie and carbody. Furthermore, because of the damping effect of the suspension system (connector elements), the acceleration amplitude and vibration frequency of the bogie and carbody are greatly reduced.

It can be seen from Figure 10(b) that the frequency components of the axle mainly consist of a low frequency of $27 \mathrm{~Hz}$ and a high frequency of $128 \mathrm{~Hz}$. The high frequency component is caused by the excitation of fasteners (springdashpot elements), which can be verified as follows. The spacing $(L)$ of the fasteners is $0.65 \mathrm{~m}$; then, the excitation period $(T)$ is as follows:

$$
T=L / v
$$

where $v$ is the train speed taken as $300 \mathrm{~km} / \mathrm{h}$ or $83.33 \mathrm{~m} / \mathrm{s}$. The excitation frequency $f$ is determined as follows:

$$
f=1 / T=v / L=83.33 / 0.65=128.2 \mathrm{~Hz} .
$$

The results coincide well with the high frequency component of the axle obtained from the numerical results. For the low frequency component, it is mainly caused by the interaction between the axle and the bogie. On the whole, the vibration frequency of the vehicle obtained from this FE model is close to the test results measured by Alves Ribeiro [39], which further indicates that the model is reliable.

In addition, the vibration response of the vehicle at the connections ( $x=10.2 \mathrm{~m}$ or $x=36.2 \mathrm{~m}$ ) between the transition section and the tunnel (or abutment) is slightly higher than that at other positions due to the sudden change of wheel-rail interaction caused by the stiffness difference (Figure 10(a)). To ensure the stable operation of the train and the comfort of passengers, the standard [40] stipulates that the vertical acceleration of the carbody with excellent passenger comfort level shall be less than $2.45 \mathrm{~m} / \mathrm{s}^{2}$. As can be seen from Figure 10(a), 

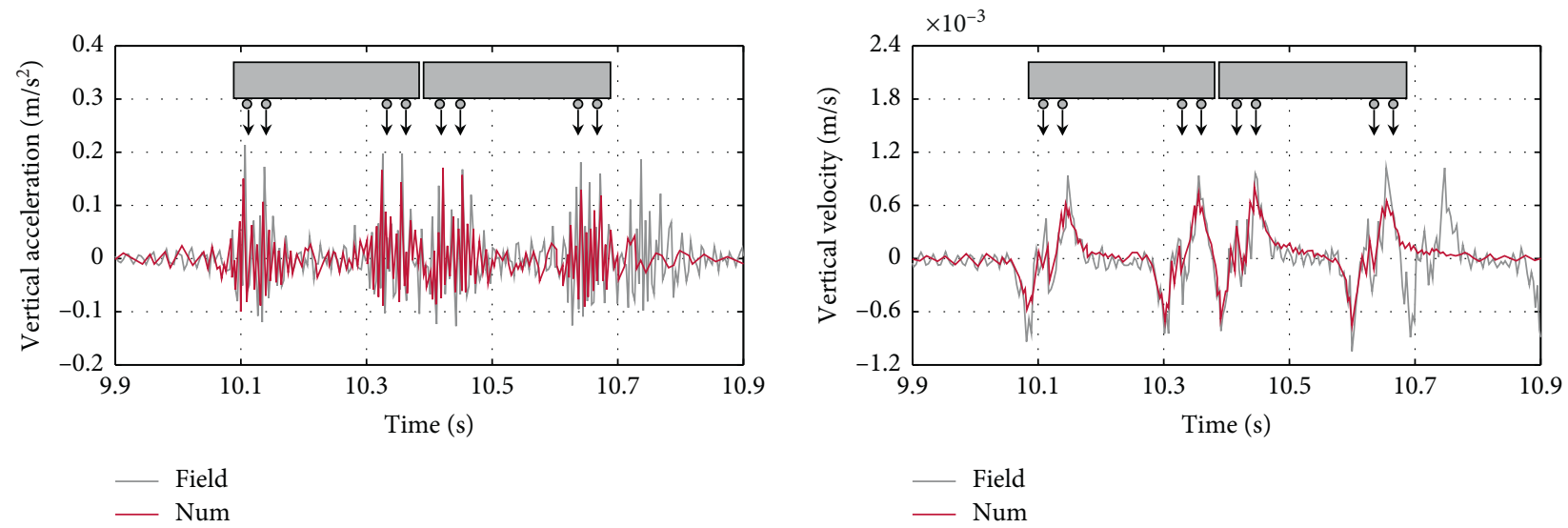

(a)
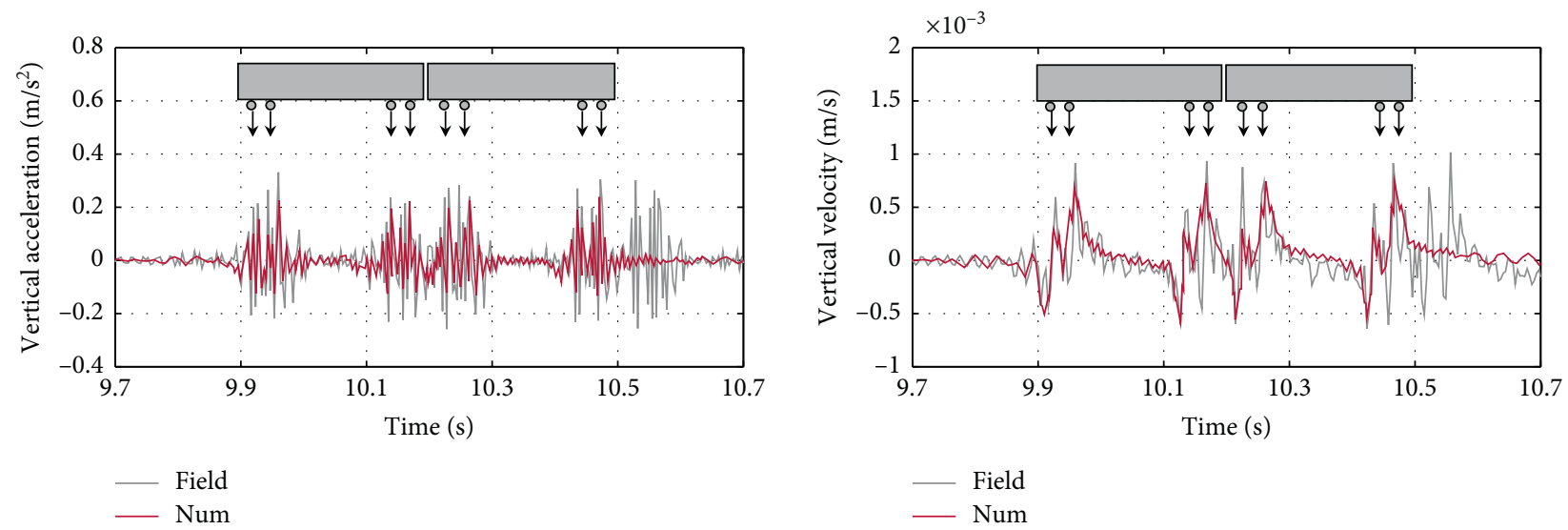

(b)
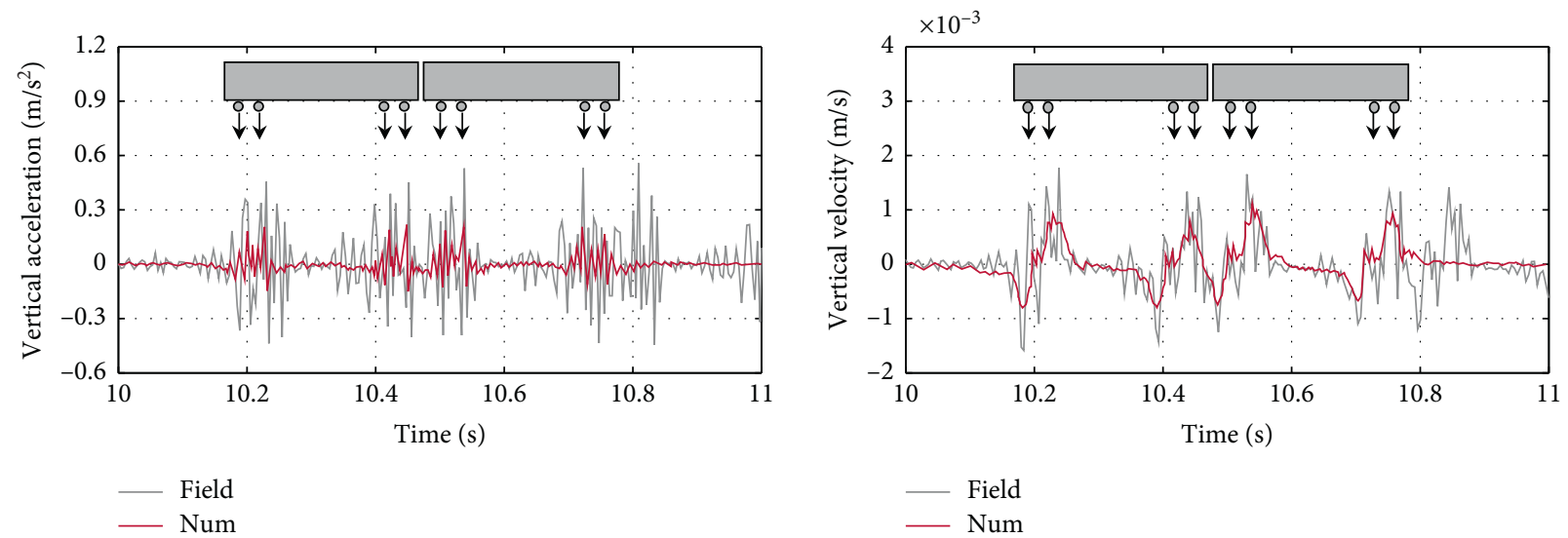

(c)

FIgURE 7: Comparison of time-history curves between the numerical results and the field measurement. (a) B0-3. (b) S1-3. (c) T0-3.

the maximum vertical acceleration of the carbody is $0.75 \mathrm{~m} / \mathrm{s}^{2}$, indicating the train reaches an excellent comfort level, and the DBPPS transition section fulfills its purpose in that it provides a smooth stiffness transition.

4.2. Distribution of Vertical Dynamic Stress in the Subgrade. To analyze the vertical dynamic stress distribution in the subgrade when the train passes by, some observation points at sections of $\mathrm{S} 1, \mathrm{~S} 2$, and $\mathrm{S} 3$ in the FE model were selected, as shown in Figure 11. Observation points of P1, P3, and P5 are located on the subgrade surface below the line center, and observation points of P2, P4, and P6 are located on the subgrade surface directly below the rail. Figure 11 shows the time-history curves of vertical dynamic stress at these observation points. It can be seen that the vertical dynamic stress on the subgrade surface at observation points of $\mathrm{P} 2$, P4, and P6 is $17 \% \sim 18 \%$ higher than that at observation 

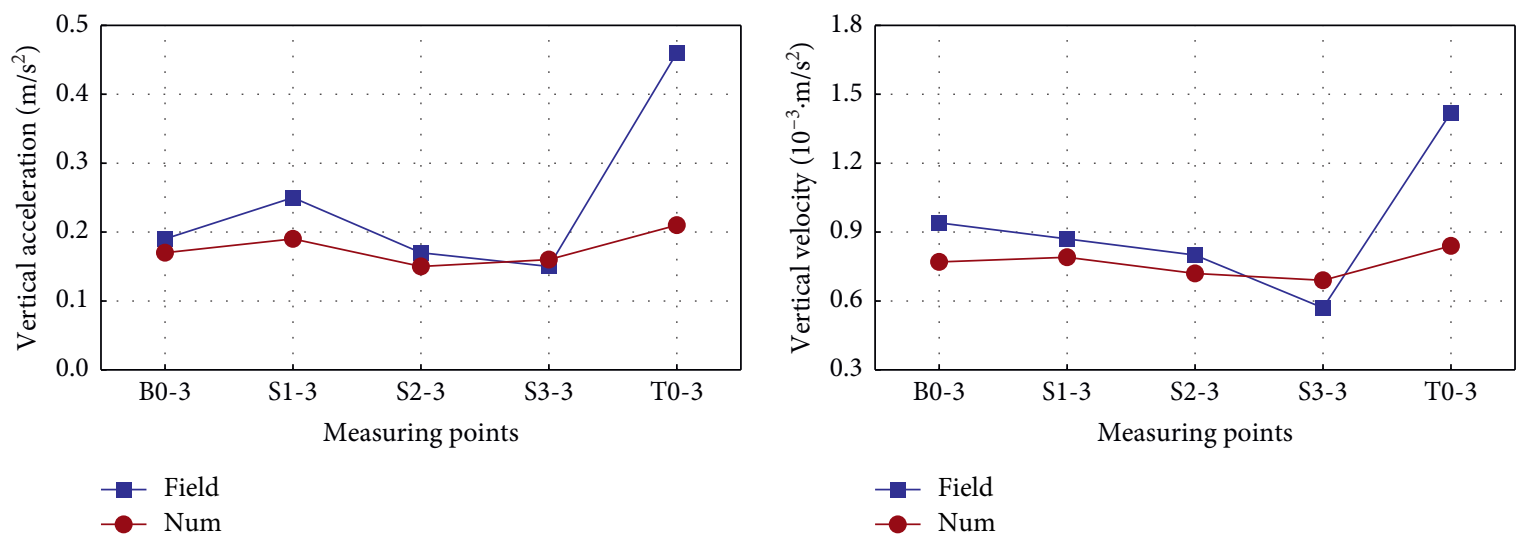

(a)
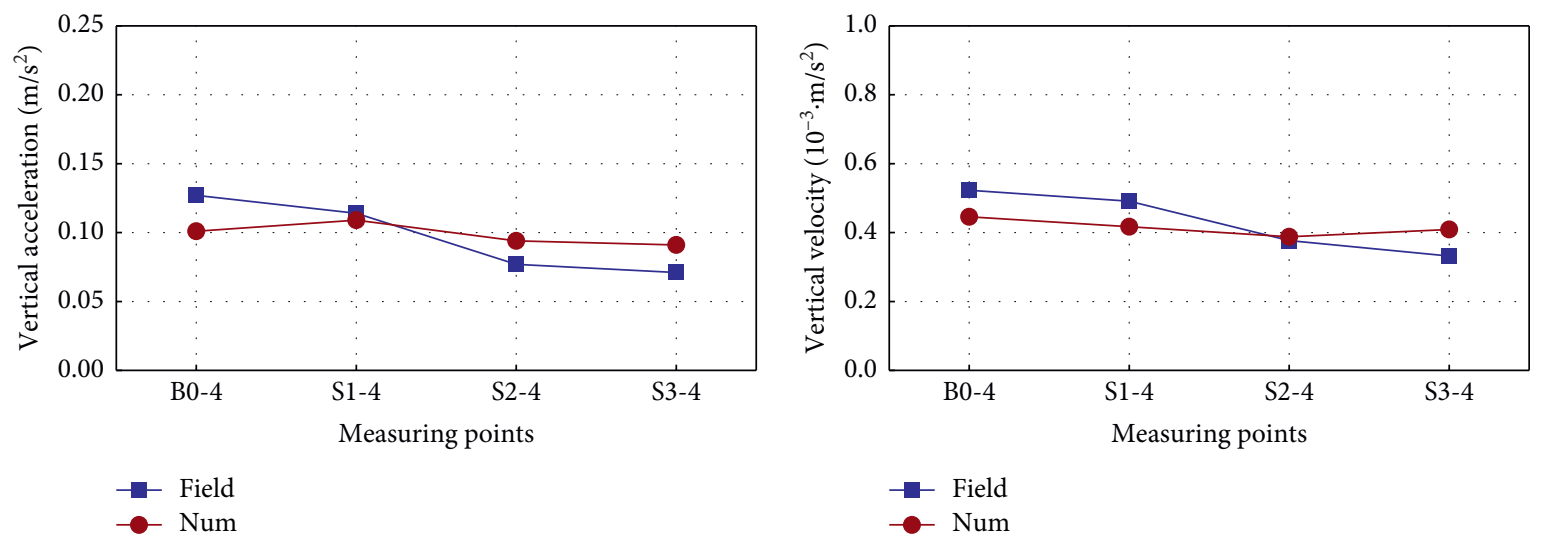

(b)

Figure 8: Comparison of vertical acceleration and velocity peaks between the numerical results and the field measurement. (a) Measuring points on the base slab. (b) Measuring points on the subgrade center.

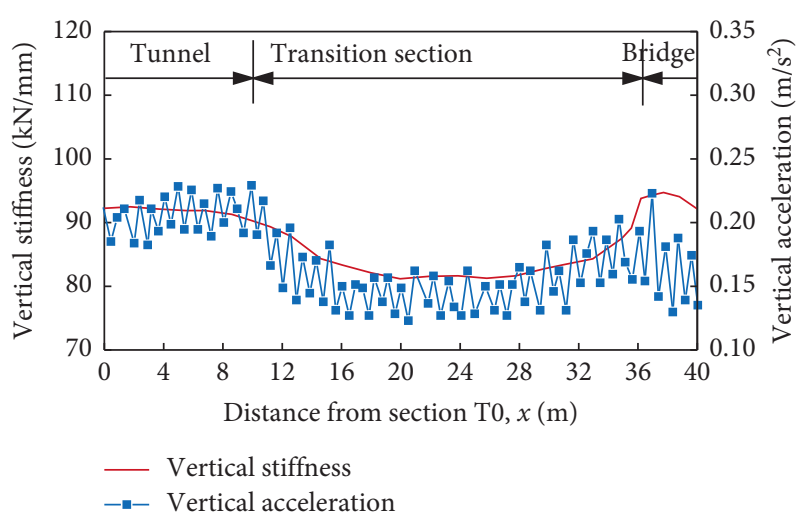

Figure 9: Distribution of the vertical acceleration and track stiffness along the transition zone.

points of P1, P3, and P5. More importantly, the vertical dynamic stress of section S1 is higher than that of sections S2 and S3. Figure 12 visually shows the vertical dynamic stress contour of the train passing through section $\mathrm{S} 1$ and section S3 successively. The maximum vertical dynamic stress of section $\mathrm{S} 1$ is higher than that of section $\mathrm{S} 3$, which verifies the existence of the additional load mentioned above. It becomes evident that when the train moves from the bridge to the tunnel, the additional load caused by the train load increases the dynamic stress on the subgrade surface of section S1, which is also the reason why the vibration responses of section S1 are higher than that of sections S2 and S3 in the field measurement (see Figure 8).

4.3. Influences of Train Speed, Axle Weight, and Direction on Dynamic Response. To investigate the influences of different factors on the dynamic responses of the transition section, three factors, including train speed, axle weight, and running direction, are selected for sensitivity analysis. Figure 13(a) shows the relationship between the vertical acceleration on the base slab and the train speed. With the train speed increasing from $200 \mathrm{~km} / \mathrm{h}$ to $400 \mathrm{~km} / \mathrm{h}$, the vertical acceleration also increases, in which the vertical acceleration increases from $0.20 \mathrm{~m} / \mathrm{s}^{2}$ to $0.44 \mathrm{~m} / \mathrm{s}^{2}$ at measuring point T03 , and increases from $0.007 \mathrm{~m} / \mathrm{s}^{2}$ to $0.30 \mathrm{~m} / \mathrm{s}^{2}$ at measuring point S3-3. If the aerodynamic effect mentioned above is not considered in practice, even if the train speed reaches $400 \mathrm{~km} / \mathrm{h}$, the vertical acceleration on the base slab is less than $5.0 \mathrm{~m} / \mathrm{s}^{2}$ specified in the code [8], indicating that the track structure is still in safe service.

In addition, with the train speed increasing from $200 \mathrm{~km} / \mathrm{h}$ to $400 \mathrm{~km} / \mathrm{h}$, the dynamic stress at observation 


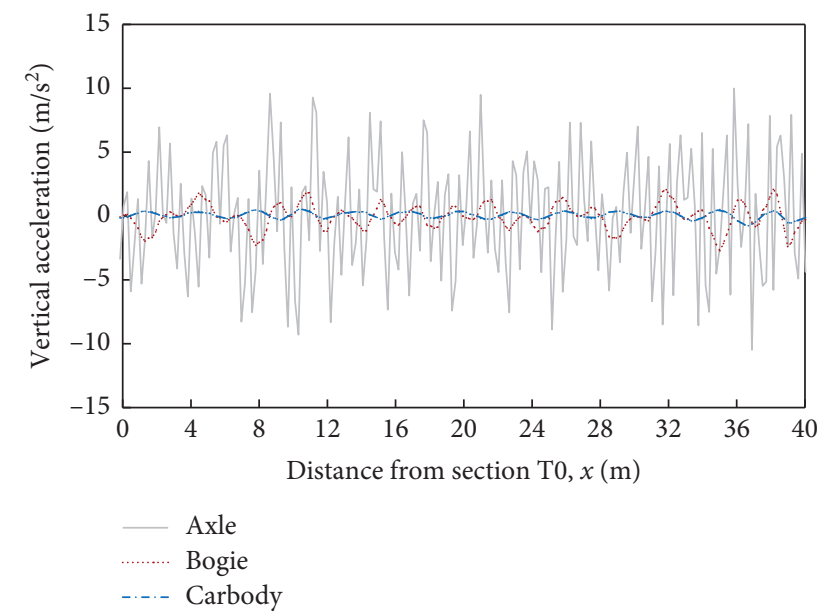

(a)
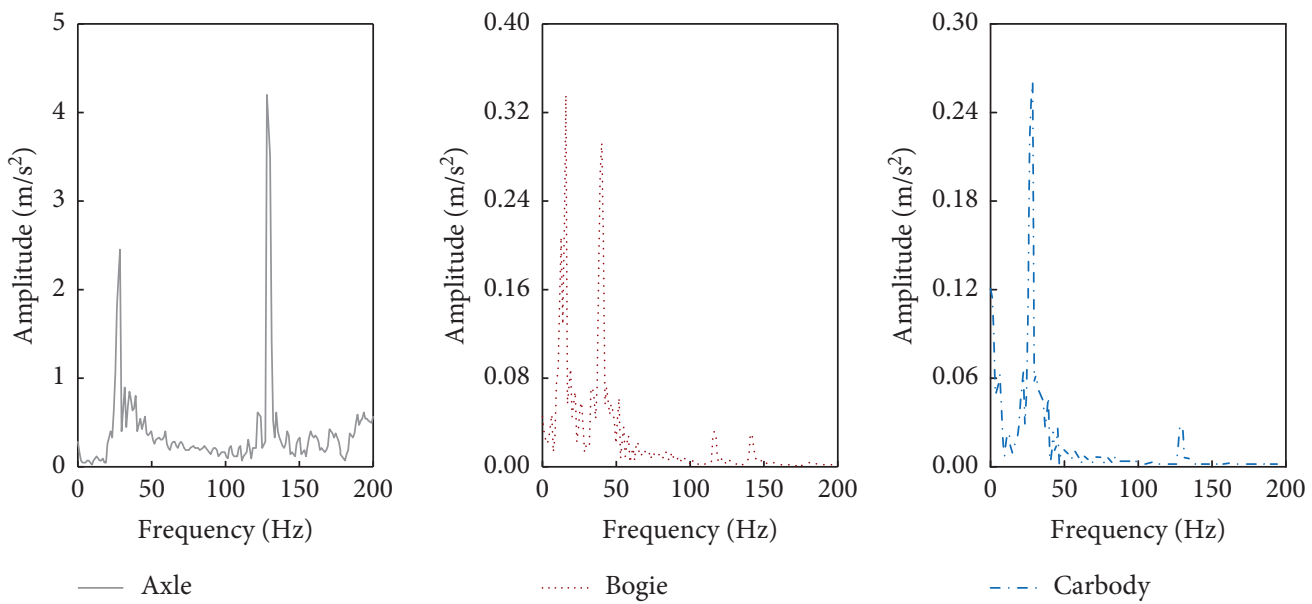

(b)

Figure 10: Vertical acceleration distribution of the train along the transition zone. (a) Acceleration. (b) Frequency.

points P4 and P6 is almost unchanged, as shown in Figure 13(b). Nevertheless, the dynamic stress at observation point P2 (at section S1) increases slightly from $30.5 \mathrm{kPa}$ to $31.6 \mathrm{kPa}$. The authors consider that the increase of dynamic stress at observation point P2 is related to the additional load, and with the increase of train speed, the additional load caused by train load also increases in the connections with a large stiffness difference.

Figure 14(a) shows the relationship between the vertical acceleration on the base slab and the axle weight. With the axle weight increasing from $10 t$ to $30 t$, the vertical acceleration increases approximately exponentially, and the vertical dynamic stress increases approximately linearly (Figure 14(b)). Consequently, the axle weight is quite sensitive to the dynamic responses of the DBPPS transition section.

To reflect the influence of train direction on the dynamic responses, except for the vertical acceleration at original observation points, the authors also select the vertical acceleration from other observation points at both sides of the connections (i.e., $x=10.2 \mathrm{~m}$ and $x=36.2 \mathrm{~m}$ ), where $x=8.9 \mathrm{~m}, 11.5 \mathrm{~m}, 34.9 \mathrm{~m}$, and $37.5 \mathrm{~m}$, as shown in Figure 15 . When the train moves from the tunnel to the bridge, the amplification effect can be observed at $x=11.5 \mathrm{~m}$ and $x=37.5 \mathrm{~m}$, while when the train moves from the bridge to the tunnel, the amplification effect occurs near $x=8.9 \mathrm{~m}$ and $x=34.9 \mathrm{~m}$. It can be concluded that under different train directions, the position with an amplification effect for vibration is also different, which is determined by the position and stiffness difference of the connections.

4.4. Optimization of Pile Length in the Pile-Plank Structure. In the case study described in Section 2, an improvement strategy with varying-length piles is adopted to achieve a better transition due to the thickness of soft soil is uneven (Figure 2). Figure 16 shows the vertical displacement on the pile top for different pile lengths. It can be seen that the vertical displacement on the pile top is negatively correlated with the pile length. The main reason is that the piles with longer pile length can transfer the upper load to a deeper bearing layer. But for shorter piles, they bear the upper load together with the shallow soil with a lower stiffness, resulting in higher vertical displacement on the pile top. According to the distribution of vertical 


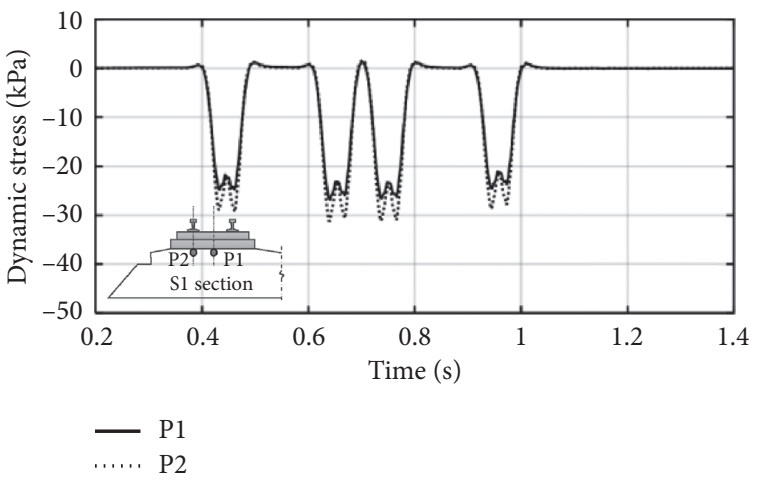

(a)

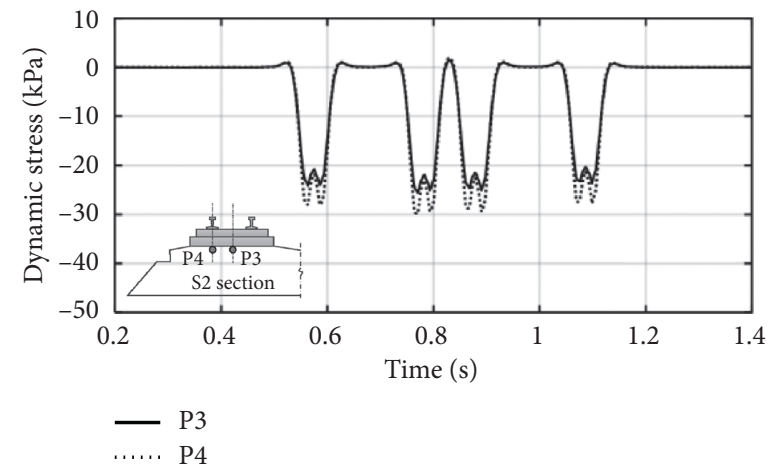

(b)

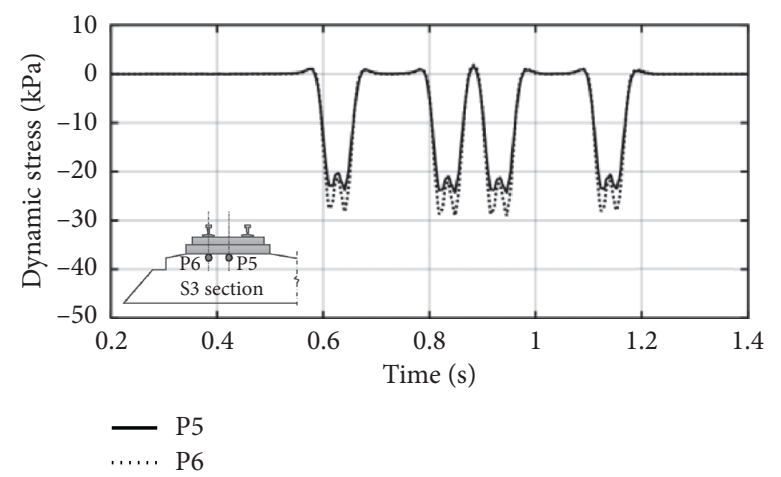

(c)

FIgURE 11: Time-history curves of the vertical dynamic stress. (a) Observation points of section S1. (b) Observation points of section S2. (c) Observation points of section S3.

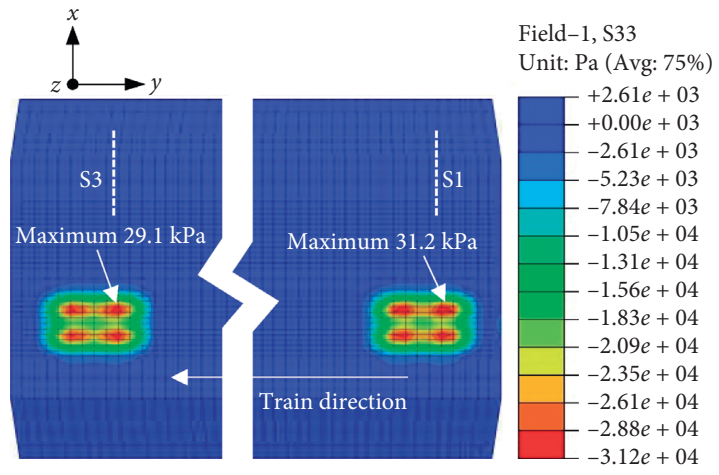

FIgURE 12: Vertical stress contour of the train passing through section S1 and section S3 successively.

displacement for different pile lengths, the strategy of varying-length piles is conducive to the stiffness smoothness in the transition zone.

For general soil layers with uniform thickness, Li and Bian [30] discussed the influences of varying-length piles and constant-length piles on the vertical track stiffness in a subgrade-bridge transition section and found that the varying-length piles strategy can effectively smooth the vertical track stiffness transition. Nevertheless, for the DBPPS transition section under the general conditions, the necessity of variable pile-length design is still debatable. In this study, four comparative cases, including two improvement strategies: varying-length piles and constant-length piles, are established to investigate the influences of pile length and the properties of soil on the DBPPS transition section, as shown in Figure 17. In these cases, it is assumed that the ground consists of two horizontal soil layers; the upper layer is the silty clay layer, the bearing layer is the sand layer or limestone layer with a higher stiffness than the silty clay layer. The material properties are shown in Table 1, and other parameters and work conditions remain unchanged.

Figure 18 shows the vertical track stiffness distribution along the transition zone under four cases. It can be seen that the smoothness of vertical track stiffness along the transition section can be improved by adopting the strategy of varyinglength piles, especially when the bearing layer is the sand layer. The authors consider that when the bearing layer is limestone, the bearing mode is similar to end-bearing piles, and the upper load is mainly transferred by piles to the bearing layer. Consequently, the change in pile length has a small effect on the upper load transfer. But when the bearing layer is the sand layer with a lower stiffness, the bearing mode is similar to friction-bearing piles, and the upper load is mainly shared by piles and the shallow ground. The increase of pile length effectively improves the friction resistance, which indirectly enhances the overall stiffness of the ground. Therefore, the strategy of varying-length piles can effectively smooth the vertical track stiffness in the DBPPS transition section with a bearing layer of low stiffness. 


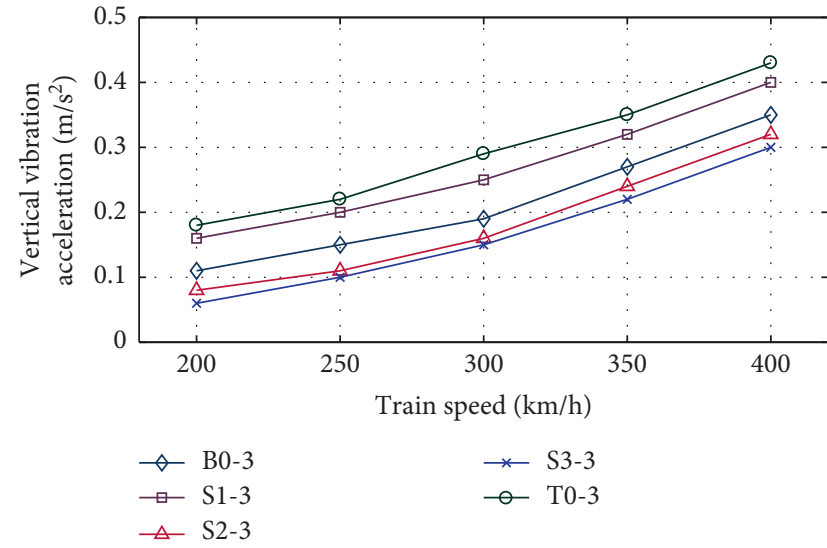

(a)

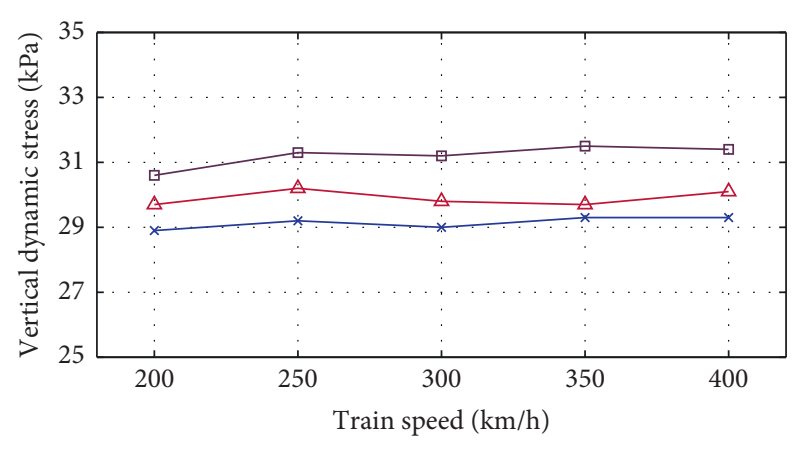

$\rightarrow \mathrm{P} 2$

$\triangle \mathrm{P} 4$

$\rightarrow$ P6

FIGURE 13: Influences of the train speed on dynamic responses. (a) Vertical acceleration. (b) Vertical dynamic stress.

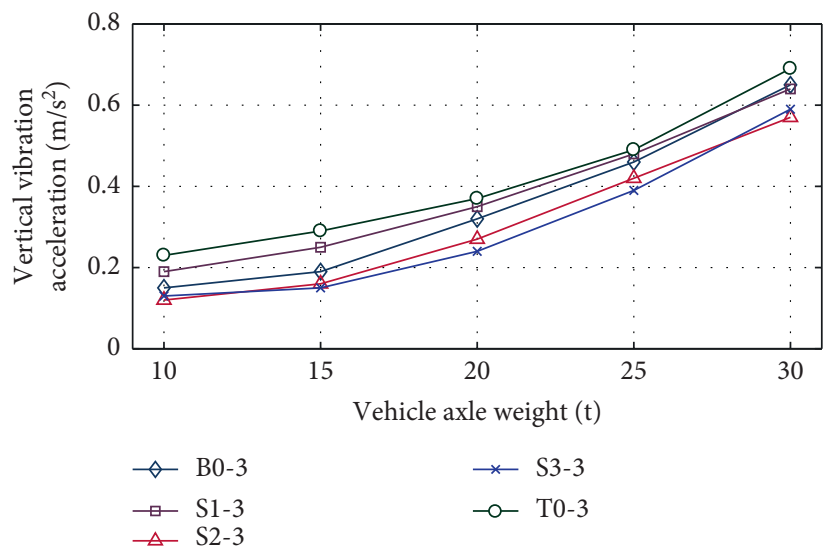

(a)

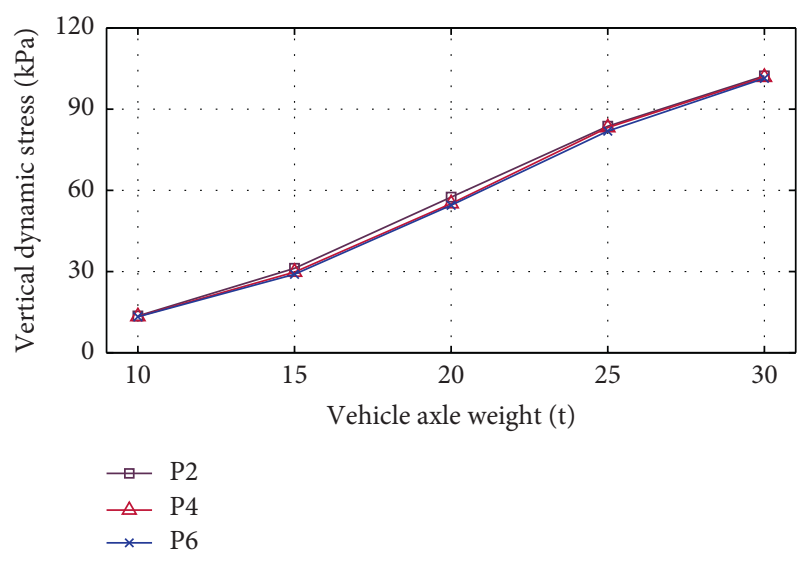

(b)

FIGURE 14: Influences of the axle weight on dynamic responses. (a) Vertical acceleration. (b) Vertical dynamic stress.

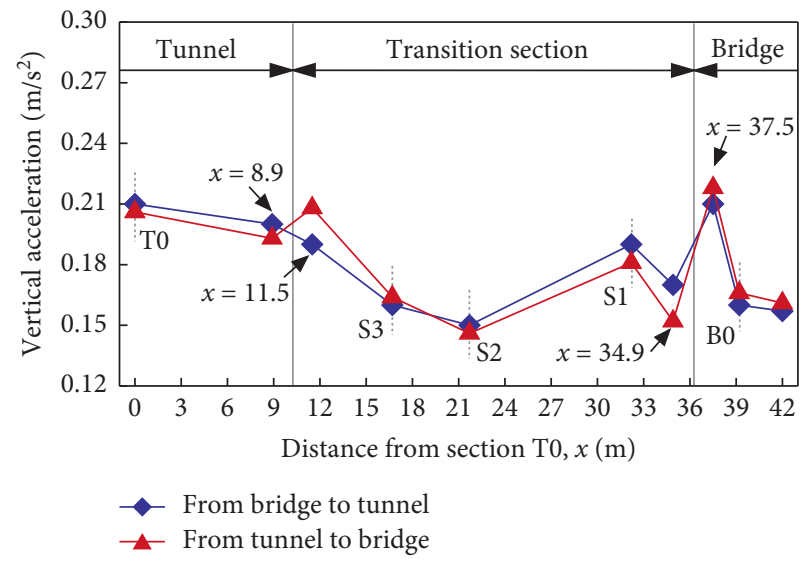

FIGURE 15: Influence of the train direction on dynamic responses.

Changes in longitudinal stresses are more prone to activate track slab cracking. Figure 19(a) shows the longitudinal stress (S22) contour on the track slab surface at a certain time for Case 3. A positive value

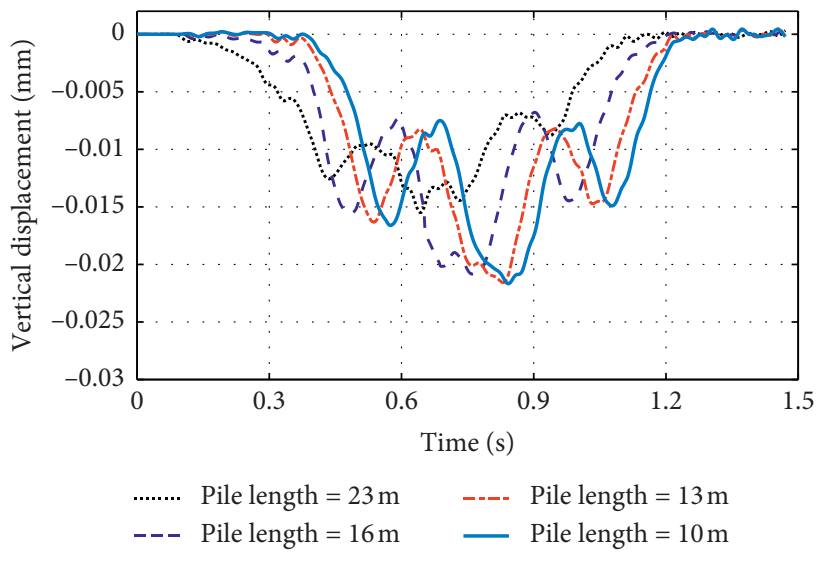

FIgURE 16: Vertical displacement on the pile top for piles of different lengths.

represents tensile stress and a negative value represents compressive stress. It can be seen that under the train load, significant concentrated tension stresses are 


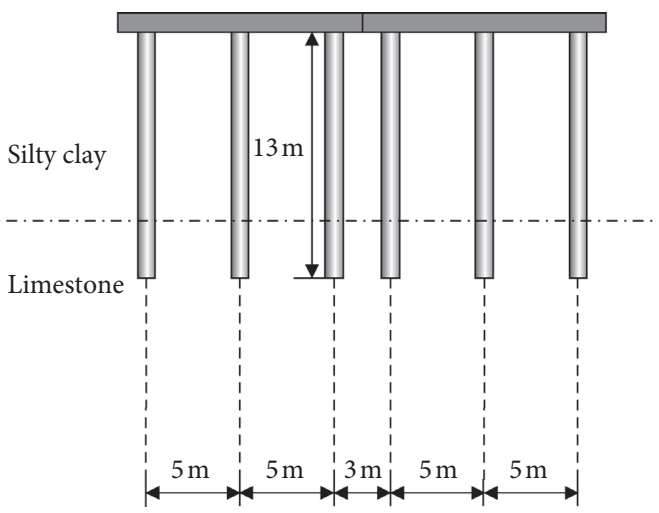

(a)

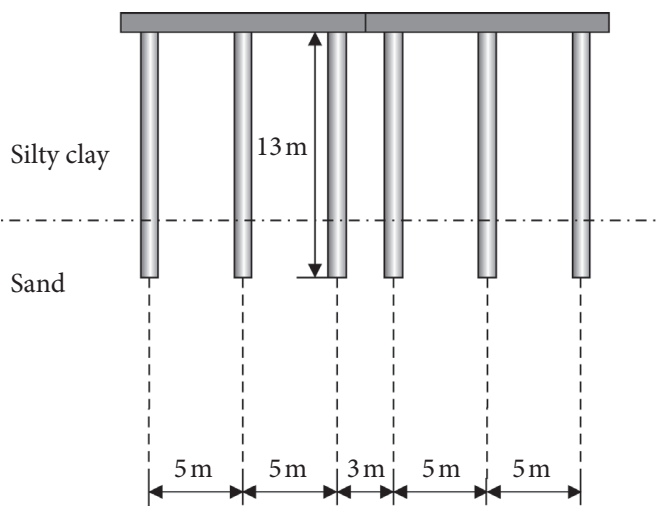

(c)

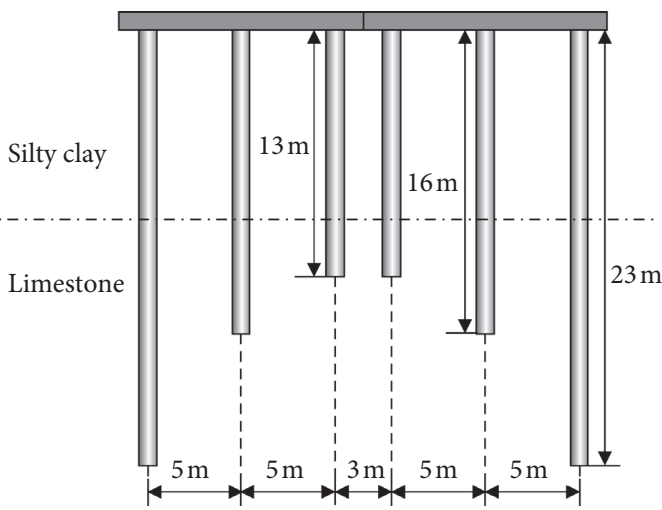

(b)

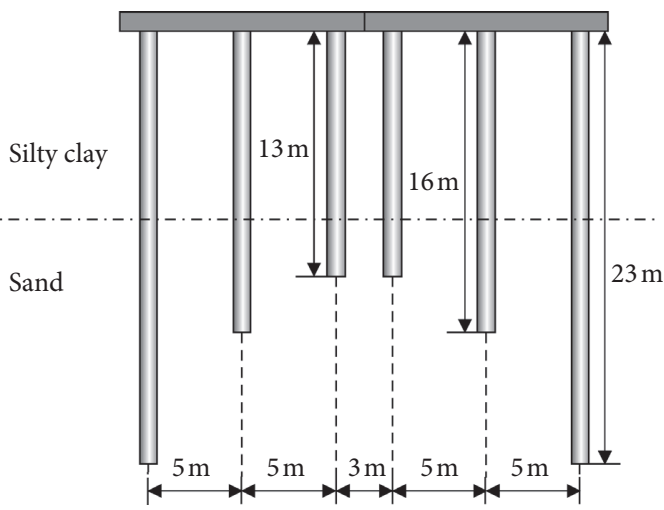

(d)

Figure 17: Optimization cases of the pile-plank structure. (a) Case 1. (b) Case 2. (c) Case 3. (d) Case 4.

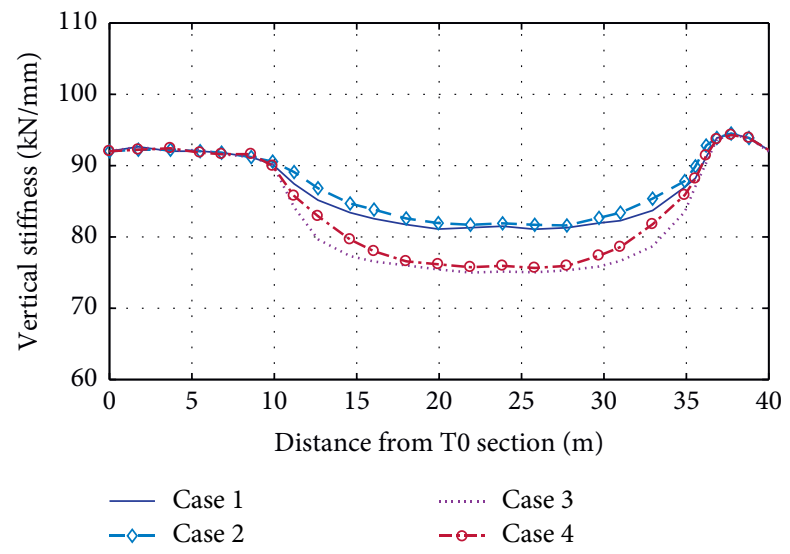

FIgURE 18: Vertical stiffness along the transition zone for different cases.

generated on the track slab surface at the positions I and II (Figure 19(a)), with the maximum value of $537.4 \mathrm{kPa}$. Nevertheless, long-term cyclic dynamic load caused by train may activate cracks at these positions.

Figure 19(b) shows the comparison of maximum tensile stress along the DBPPS transition section in four cases. The maximum tensile stresses at positions I and II are significantly higher than those at other positions due to the larger stiffness difference. When the bearing layer is limestone layer, the maximum tensile stress on the track slab surface at positions I and II can be reduced by $10.9 \%$ and $7.8 \%$, respectively, using varying-length piles, while when the bearing layer is the sand layer, the values can be reduced by $27.8 \%$ and $18.2 \%$, respectively, indicating that the strategy of varying-length piles can significantly reduce the tensile stress on the track slab surface, and the lower the stiffness of the bearing layer, the more the tensile stress reduces.

In general, to prevent cracks at the connection between abutment and transition section, expansion joints or other improved measures would be applied to address these 


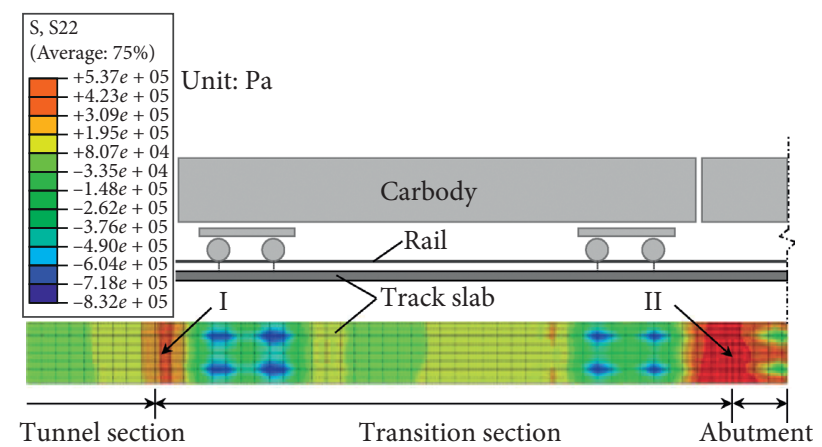

(a)

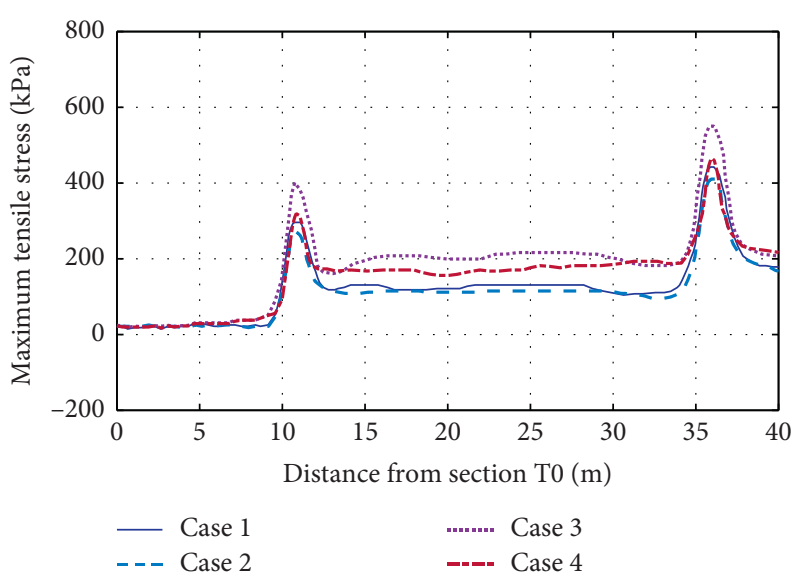

(b)

Figure 19: Tensile stress distribution for different cases. (a) Tensile stress contour of Case 3 at a certain time. (b) Maximum tensile stress for different cases.

problems in practical engineering. From the above results, the authors suggest that in addition to the connection between the bridge and the DBPPS transition section, the connection between the tunnel and the DBPPS transition section should also be reinforced or treated.

\section{Conclusions}

In this study, the authors present a numerical modeling approach to investigate the dynamic performances of a new type of bridge-tunnel transition section with a DBPPS, which can be used as a tool to improve the design and application of DBPPS subgrade. The obtained research results of this study lead to the following conclusions:

(1) The vibration level of the DBPPS transition section is lower than that of the abutment and the tunnel section when the train passes by. Meanwhile, the additional load caused by vertical track stiffness difference can aggravate the vibration at the connections and its adjacent areas (such as section S1) between the DBPPS transition section and the abutment (or tunnel). In addition, the vertical acceleration of the carbody also shows abrupt change at these connections.

(2) With train speed increases, the vertical acceleration of the base slab increases, and the vertical dynamic stress on the subgrade surface near the connections (such as section S1) also increases. With axle weight increases, the vertical acceleration increases approximately exponentially, and the vertical dynamic stress increases approximately linearly. The train direction has a significant influence on the connections and its adjacent areas with a large stiffness difference.

(3) For general soil layers with uniform thickness, the improvement strategy with varying-length piles can effectively smooth the track stiffness and reduce the tensile stress on the track slab surface at the connections, and the effect is more significant when the stiffness of the bearing layer is low.

\section{Data Availability}

The data used to support the findings of this study are available from the corresponding author upon request.

\section{Conflicts of Interest}

The authors declare that they have no conflicts of interest regarding the publication of this paper.

\section{Acknowledgments}

This paper reports research developed under financial support provided by the Key Project of Science and Technology Research and Development Program of China Railway Corporation (Grant No. 2014T003-D) and the National Natural Science Foundation of China (Grant nos. 51878671 and 51678575).

\section{References}

[1] X. Lei, "Effects of abrupt changes in track foundation stiffness on track vibration under moving loads," Journal of Vibration Engineering, vol. 19, no. 2, pp. 195-199, 2006.

[2] A. Paixão, E. Fortunato, and R. Calçada, "Transition zones to railway bridges: track measurements and numerical modelling," Engineering Structures, vol. 80, pp. 435-443, 2014.

[3] K. K. Ang and J. Dai, "Response analysis of high-speed rail system accounting for abrupt change of foundation stiffness," Journal of Sound and Vibration, vol. 332, no. 12, pp. 29542970, 2013.

[4] P. Hölscher and P. Meijers, Literature Study of Knowledge and Experience of Transition Zones, Report of GeoDelft, Delft, Netherlands, 2007.

[5] European Committee for Standardisation(CEN), Basis of structural design, European Committee for Standardisation(CEN), Brussels, Belgium, 2005. 
[6] The Swedish Rail Administration, Design standard for railway bridges, Standard BVS 583.10, The Swedish Rail Administration, Borlänge, Sweden, 2006.

[7] Canadian Standards Association-International, Canadian Highway Bridge Design Code, Canadian Standards Association-International, Toronto, Canada, 2000.

[8] National Railway Administration, Code for Design of High Speed Railway (TB10621-2014), China Railway Publishing House, Beijing, China, 2015.

[9] D. Li and D. Davis, "Transition of railroad bridge approaches," Journal of Geotechnical and Geoenvironmental Engineering, vol. 131, no. 11, pp. 1392-1398, 2005.

[10] P. Hu, C. Zhang, S. J. Chen, Y. Wang, W. Wang, and W. H. Duan, "Dynamic responses of bridge-embankment transitions in high speed railway: field tests and data analyses," Engineering Structures, vol. 175, pp. 565-576, 2018.

[11] Y. Shan, B. Albers, and S. A. Savidis, "Influence of different transition zones on the dynamic response of track-subgrade systems," Computers and Geotechnics, vol. 48, pp. 21-28, 2013.

[12] Y. Shan, Y. Shu, and S. Zhou, "Finite-infinite element coupled analysis on the influence of material parameters on the dynamic properties of transition zones," Construction and Building Materials, vol. 148, no. 1, pp. 548-558, 2017.

[13] J. Ren, H. Zhao, X. Li et al., "Dynamic performances of CRTS III prefabricated slab track with anti-vibration structure in subgrade-tunnel transition section," Journal of Southwest Jiaotong University, vol. 51, no. 6, pp. 1047-1054, 2016.

[14] J. N. Varandas, P. Hölscher, and M. A. G. Silva, "Three-dimensional track-ballast interaction model for the study of a culvert transition," Soil Dynamics and Earthquake Engineering, vol. 89, pp. 116-127, 2016.

[15] P. Hu, C. Zhang, S. Wen, and Y. Wang, "Dynamic responses of high-speed railway transition zone with various subgrade fillings," Computers and Geotechnics, vol. 108, pp. 17-26, 2019.

[16] J. N. Varandas, A. Paixão, and E. Fortunato, "A study on the dynamic train-track interaction over cut-fill transitions on buried culverts," Computers \& Structures, vol. 189, no. 9, pp. 49-61, 2017.

[17] R. Sañudo, L. Dell'Olio, J. A. Casado, I. A. Carrascal, and S. Diego, "Track transitions in railways: a review," Construction and Building Materials, vol. 112, pp. 140-157, 2016.

[18] L. Wei, C. He, and Z. Yang, Comprehensive Test Study Report of Nanchang West to Yichun East Section of ShanghaiKunming Railway Passenger Dedicated Line, Central South University, Changsha, China, 2014.

[19] Q. Su, W. Wang, H. Bai et al., "Bearing capacity mechanism of non-embedded pile-plank structure subgrade," Journal of Traffic and Transportation Engineering, vol. 12, no. 1, pp. 19-24, 2012.

[20] Y.-X. Zhan, H.-L. Yao, and G.-L. Jiang, "Design method of pile-slab structure roadbed of ballastless track on soil subgrade," Journal of Central South University, vol. 20, no. 7, pp. 2072-2082, 2013.

[21] K. Ma, "Analysis on space vibration performance of pile-plank structure-foundation soil system under the condition of high-speed trains running," Journal of the China Railway Society, vol. 35, no. 1, pp. 93-100, 2013.

[22] L. Huang, B. Wang, and S. Zhou, "Centrifugal model test of pile-plank subgrade in soft ground," Rock and Soil Mechanics, vol. 34, no. S1, pp. 192-196, 2013.

[23] J. Huang, Q. Su, T. Liu, and X. Wang, "Vibration and longterm performance analysis of pile-plank-supported low subgrade of ballastless track under excitation loads," Shock and Vibration, vol. 2015, pp. 1-12, 2015.
[24] Dassault Systemes Simulia Corp, Abaqus Analysis User's Manual, Version 6.12, Dassault Systemes Simulia Corp, Johnston, Rhode Island, USA, 2012.

[25] C. Cheng, "Study on dynamic responses of irregularity ballastless track for high-speed railway," PhD Thesis, Zhejiang University, Zhejiang, China, 2015.

[26] H. Hertz, "On the contact of elastic solids," Journal für die rne und angewandte Mathematik (Crelles Journal), vol. 92, no. 156, 2008.

[27] P. Ni, K. Wang, W. Zhang et al., "Calculation method of wheel-rail contact relation," Journal of Traffic and Transportation Engineering, vol. 04, pp. 14-17, 2006.

[28] W. Zhai and X. Sun, "A detailed model for investigating vertical interaction between railway vehicle and track," Vehicle System Dynamics, vol. 23, pp. 603-615, 1994.

[29] W. Zhai, Vehicle-track Coupled Dynamics: Theory and Application, Science Press and Springer Nature Singapore Pte Ltd., Berlin, Germany, 2020.

[30] W. Li and X. Bian, "Dynamic performance of pile-supported bridge-embankment transition zones under high-speed train moving loads," Procedia Engineering, vol. 143, pp. 1059-1067, 2016.

[31] P. Ni, S. Mangalathu, G. Mei, and Y. Zhao, "Permeable piles: an alternative to improve the performance of driven piles," Computers and Geotechnics, vol. 84, pp. 78-87, 2017.

[32] K. Liu, Q. Su, P. Ni, C. Zhou, W. Zhao, and F. Yue, "Evaluation on the dynamic performance of bridge approach backfilled with fibre reinforced lightweight concrete under high-speed train loading," Computers and Geotechnics, vol. 104, pp. 42-53, 2018.

[33] F. Xue and J. Zhang, "Attenuations of acceleration spectra of high-speed railway embankment subjected to moving loads," Rock and Soil Mechanics, vol. 36, pp. 445-451, 2015.

[34] Y. Xuan, "Simulation research on the dynamic characteristics of vehicle-track coupling system on curved track and the vibration response of ballastless track strucure of passenger traffic railway," PhD Thesis, China Academy of Railway Sciences, Beijing, China, 2008.

[35] P. Ricco, A. Baron, and P. Molteni, "Nature of pressure waves induced by a high-speed train travelling through a tunnel," Journal of Wind Engineering and Industrial Aerodynamics, vol. 95, no. 8, pp. 781-808, 2007.

[36] C. Esveld, Modern Railway Track, MRT-Productions, Zaltbommel, Netherlands, 2001.

[37] R. Sañudo, M. Cerrada, B. Alonso, and L. dell'Olio, “Analysis of the influence of support positions in transition zones. A numerical analysis," Construction and Building Materials, vol. 145, no. 1, pp. 207-217, 2017.

[38] M. Shahraki, C. Warnakulasooriya, and K. J. Witt, "Numerical study of transition zone between ballasted and ballastless railway track," Transportation Geotechnics, vol. 3, pp. 58-67, 2015.

[39] C. Alves Ribeiro, R. Calçada, and R. Delgado, "Experimental assessment of the dynamic behaviour of the train-track system at a culvert transition zone," Engineering Structures, vol. 138, no. 1, pp. 215-228, 2017.

[40] Ministry of Railways Institute of Standard Metrology, Railway Locomotive Dynamic Performance Test Identification Method and Evaluation Standard (TBT2360-1993), Ministry of Railways Institute of Standard Metrology, Beijing, China, 1994. 